\title{
EFSUMB Guidelines and Recommendations on the Clinical Use of Ultrasound Elastography. Part 2: Clinical Applications
}

Authors

Affiliations
D. Cosgrove ${ }^{1}$, F. Piscaglia' ${ }^{2}$, J. Bamber ${ }^{3}$, J. Bojunga ${ }^{4}$, J.-M. Correas ${ }^{5}$, O. H. Gilja ${ }^{6}$, A. S. Klauser ${ }^{7}$, I. Sporea ${ }^{8}$, F. Calliada ${ }^{9}$, V. Cantisani ${ }^{10}$, M. D’Onofrio ${ }^{11}$, E. E. Drakonaki ${ }^{12}$, M. Fink ${ }^{13}$, M. Friedrich-Rust ${ }^{14}$, J. Fromageau ${ }^{3}$, R. F. Havre ${ }^{15}$, C. Jenssen ${ }^{16}$, R. Ohlinger ${ }^{17}$, A. Săftoiu ${ }^{18}$, F. Schaefer ${ }^{19}$, C. F. Dietrich ${ }^{20}$

Affiliation addresses are listed at the end of the article.

\author{
Key Words \\ - breast \\ - elastography \\ - liver \\ - strain \\ - shear waves \\ - stiffness \\ - thyroid \\ ultrasound
}

\section{Bibliography}

Dol http://dx.doi.org/ 10.1055/s-0033-1335375

Published online: April 19, 2013

Ultraschall in Med 2013; 34:

238-253 @ Georg Thieme

Verlag KG Stuttgart · New York . ISSN 0172-4614

\section{Correspondence}

David O. Cosgrove,

Div. of Radiology,

Hammersmith Hospital,

Du Cane Road,

London, W12 $\mathrm{OHS}$,

UK

d.cosgrove@imperial.ac.uk

\section{Zusammenfassung}

$\nabla$

Der klinische Teil dieser unter der Schirmherrschaft der EFSUMB erstellten Richtlinien und Empfehlungen beurteilt die klinisch genutzten Anwendungen aller Formen der Elastografie, betont die Evidenz von Meta-Analysen und gibt praktische Hinweise in Bezug auf Einsatz und Interpretation der Elastografie. Die diffusen Lebererkrankungen nehmen den größten Teil ein und spiegeln somit die umfangreiche Erfahrung in der transienten und der ShearWave-Elastografie wider. Es folgen Brust, Schilddrüse, Gastrointestinaltrakt, endoskopische Elastografie, Prostata und Muskel-SkelettSystem unter Verwendung von Strain und gegebenenfalls ShearWave-Elastografie. Diese Publikation soll als Empfehlung dienen und klinische Anwender auf praktische Art anleiten.

\section{Introduction}

This report is divided into a first paper that deals with the underlying physical principles [1] and this second paper that covers the most important clinical applications. Both the technology and the clinical applications are developing rapidly. This set of Guidelines, which provides a snapshot of the state of the art, will therefore no doubt soon need refreshing.

Two main forms of elastography have become established in clinical practice, though other important implementations are to be expected as the field matures. In the first, known as quasistatic or strain elastography (SE), the tissue deformation produced (which is the strain) by an external palpation with the probe or by endogenous stress such as cardiovascular movements, is assessed by following the way the speckle in the image moves, usually with a tracking algorithm working on the radio-frequency data, much as is used to apply motion correction to the liver for Contrast

\section{Abstract \\ $\nabla$}

The clinical part of these Guidelines and Recommendations produced under the auspices of the European Federation of Societies for Ultrasound in Medicine and Biology EFSUMB assesses the clinically used applications of all forms of elastography, stressing the evidence from meta-analyses and giving practical advice for their uses and interpretation. Diffuse liver disease forms the largest section, reflecting the wide experience with transient and shear wave elastography . Then follow the breast, thyroid, gastro-intestinal tract, endoscopic elastography, the prostate and the musculo-skeletal system using strain and shear wave elastography as appropriate. The document is intended to form a reference and to guide clinical users in a practical way.

Enhanced Ultrasound (CEUS) [2]. The data can then be used to form an image that is coded in colour or grey-scale to show the pattern of strain, which is inversely related to tissue stiffness and can be assessed subjectively. Usually the sign of the strain (i.e. whether the tissue expands or contracts along a given direction) is ignored but in a variant of this approach, the sign of the strain is displayed; this method has been used in echocardiography and for the gut. These images are semiquantitative and do not directly depict the elasticity (i. e. the stress/strain ratio, or Young's modulus); there are technical reasons for this, mainly the difficulty of measuring the amount of stress within the tissue that is due to the force applied at the surface. However, regions of interest (ROIs) can be drawn over target areas in the screen and over an adjacent reference region, if a reference normal tissue can be found that is likely to be experiencing the same stress as the target region, and the ratio calculated to provide a semi-quantitative analysis. 
The second form that is currently implemented is shear wave elastography (SWE). Shear waves may not be familiar to clinical readers but they frequently occur in human soft tissues. They have similarities with the ultrasonic waves used for conventional ultrasound imaging, both being mechanical waves that are conducted by soft tissue, but there are also key differences. Shear waves are transverse (i. e. the particle movement is across the direction of travel, as occurs in the ripples of a water surface when it is disturbed); they are rapidly attenuated by tissue; they travel much more slowly (between 1 and $10 \mathrm{~m} / \mathrm{s}$ ) and they are not supported by liquids of low viscosity. Their speed is closely related to Young's modulus of elasticity and there is a simplified formula for converting, with some assumptions, between $c_{s}$ (the shear wave speed) and $E$ (Young's modulus). Shear waves are produced by any mechanical disturbance and occur naturally from muscular movements (voluntary, cardiac etc.) as well as being induced by the ultrasound systems used to measure their speed. The methods are described in greater detail in Part 1 of these Recommendations [1] and are only briefly summarized here.

In one system developed for liver fibrosis assessment, known as transient elastography (TE), a mechanical piston concentrically mounted with a single-element ultrasound transducer is used to apply a light push to the skin over an intercostal space. The travel of the resulting shear wave into the liver along the direction of the ultrasound beam is used to measure its speed in a manner similar to M-mode.

A useful way to generate shear waves is to use acoustic radiation force: tiny displacements in soft tissue set up shear waves that travel sideways away from the "pushing" ultrasound beam. Though the amplitude of the resulting shear waves is minute (a few microns' displacement), they can be detected by conventional ultrasound using tracking algorithms. An acoustic radiation force impulse (ARFI) may be employed to generate a shear-wave pulse, allowing its speed to be measured locally with good spatial resolution.

Shear wave speed measurement elastography comes in three flavours [1]: in one, a small measurement box (usually $5 \times 10 \mathrm{~mm}$ ) is set up within the tissue and readings of the shear wave speed are made. This modality may be considered as point SWE (pSWE). In a second, this is extended to sequential multiple pushing and measurement points, so that a single static SWE image may be built up and displayed as a colour-coded map of the shear wave speed (2D-SWE), which is quantitative (an ROI gives the readouts). In a third, which requires specialised hardware for ultrafast ultrasound imaging a real time imaging at approximately 1 frame per second is possible within a sensitive box. The quantitative nature of shear wave elastography is an advantage and the fact that the system displaces the tissue is expected to improve consistency since the operator does not need to move the transducer.

A final form of elastography that is currently available also uses ARFI but any shear wave generated is ignored and instead the amplitude of the displacement generated in the vicinity of the pushing beam's focus is displayed and used as a surrogate for the inverse of Young's modulus. Such displacement lasts only milliseconds and an image must be built slowly from multiple positions of the pushing focus, producing a qualitative static elastogram. As with SWE the fact that the system moves the tissue is expected to improve consistency. The localised nature of the applied force should also improve the relationship between displacement and elasticity compared with applying the force at the surface, as well as improve contrast and spatial resolution.
A figure of merit is provided by many elastography scanners to reject poor quality image data, and an onscreen display may allow the rejection threshold to be set and provide visual feedback to assist the acquisition of better images. Poor quality may result from noise (for example, if the tissue under study is too deep) and uncertainty in the tracking of the displacements. Elastographic artefacts are common and need to be learned and recognised. Cysts produce patterns that depend on the particular scanner used.

In practice, elastography forms an extension of conventional ultrasonography, much in the same way as Doppler is integrated into clinical practice. It is unhelpful to compare elastography with conventional ultrasonography: more usefully, it forms a natural extension that easily integrates with conventional scanning. The combination is often much more powerful than either alone. A practical problem that remains unresolved is the different colour scales and even scale directions that are used; whether stiffer tissue is coded as blue or red and whether it is placed at the top or bottom of the scale all remain to be standardised, though at least the colour scale is a user-choice on most systems. The situation is reminiscent of the controversy over whether the B-mode display should be black-on-white or, as eventually emerged as standard, white-on-black that plagued the early days of ultrasonography. It is an indication that the subject is not yet mature but also that there is much undiscovered potential in an exciting new field. A general finding is that experience is needed to obtain reproducible elasticity readings. This is best evidenced for transient elastography. It has been shown that better results are obtained when users have performed 500 previous studies [3]. For strain elastography the rate and distance over which the probe is moved are critical to obtaining the best possible elastograms, although the trend is for systems to become increasingly tolerant to the motion used and whether any external motion is required at all. For all elastographic methods, the fact that tissue becomes stiffer as it is stressed ("compressed") is an important factor: prestress can result in misleadingly high stiffness readings, especially in superficial tissues.

More detailed information of the physical basis, technical characteristics and artefacts of each method are more extensively reported in the part 1 of these Recommendations [1].

\section{Liver \\ $\nabla$}

\section{Background}

The assessment of fibrosis in chronic liver diseases is pivotal for prognosis and guiding management, including whether to start antiviral treatment. Liver biopsy is considered the "gold-standard" for fibrosis assessment and stage classification [4] and can also grade necro-inflammatory activity, but it has limitations. It is invasive, with potential complications that are severe in up to $1 \%$ of cases $[5,6]$. The specimen represents roughly only $1 / 50000$ of the liver volume, and there is interobserver variability at microscopic evaluation [7]. Therefore, non-invasive methods for liver fibrosis assessment have been an intense field of research, including elastographic methods using ultrasound.

A difficulty with liver elastography is the proliferation of different methods which are likely not equivalent. This means that cut-off values are system-specific and cannot readily be compared across machines. Currently, transient elastography is the best-studied and further results with other methods are awaited. 
Patient-dependent factors can influence the results [8]. These confounders include changes that increase the liver's volume, such as congestive heart failure [9], exacerbations of acute hepatitis associated with transaminase flares [10] and feeding [3] all of which make the liver stiffer. Patients should be fasted for liver studies [11]. In addition, extrahepatic cholestasis [12] and the use of beta-blockers [13] increase the readings, as does held inspiration, so that transiently stopping breathing in a neutral position is optimal for measurements. The left lobe of liver is often reported to be stiffer than the right, when both lobes could be assessed $[14,15]$ and assessments should also avoid the stiffer capsule and large vessels [16].

\section{Transient elastography}

Transient elastography (TE) is performed using the FibroScan ${ }^{\circledR}$ (Echosens, Paris, France). The method is described in part 1 [1].

\section{Clinical applications}

TE is the first ultrasound-based elastographic technique for the liver, introduced in 2003, and has the largest body of evidence by far. It was initially evaluated in patients with chronic hepatitis C and later in other chronic hepatopathies [17 - 19].

In patients with chronic hepatitis C, liver stiffness (LS) values greater than $6.8-7.6 \mathrm{kPa}$ in chronic viral hepatitis patients signify a high probability of significant fibrosis $(F \geq 2)$ on biopsy. The cut-off values for predicting cirrhosis $(\mathrm{F}=4)$ range between 11.0 and $13.6 \mathrm{kPa}$. Studies show that TE is not accurate enough to distinguish between contiguous stages of fibrosis, but can differentiate absence and mild fibrosis from significant fibrosis and cirrhosis, which is more critical for decisions regarding treatment [17 - 19]. The use of TE in chronic hepatitis $C$ has been endorsed in the recommendations for the management of viral hepatitis by the European Association for the Study of the Liver [20].

In chronic hepatitis B, ALT flares are not uncommon and since acute inflammation is an independent factor affecting LS measurements, it has been suggested that cut-off values should be adapted to the ALT level [21]. Nevertheless, a recent meta-analysis in hepatitis B virus patients [22] found considerable mean AUROCs for the diagnosis of significant fibrosis (F2) and cirrhosis (F4), namely of 0.859 (95\% confidence interval [CI], 0.857 0.860 ), and 0.929 ( $95 \% \mathrm{CI}, 0.928-0.929$ ), respectively.

Comparable results have been reported in non-alcoholic fatty liver disease (NAFLD) and non-alcoholic steato-hepatitis (NASH). Wong [23] compared TE with liver biopsy in 246 consecutive NAFLD patients and revealed $91 \%$ sensitivity and $75 \%$ specificity for predicting severe fibrosis $(\mathrm{F} \geq 3)$, using a cut-off value of $7.9 \mathrm{kPa}$. Steatosis does not seem to hamper LS measurements [24-26] as it does not change the speed of shear waves, although it can attenuate them. LS measurements can be difficult in obese patients and here the new "XL" probe increases the success rate [26, 27]. A meta-analysis in recurrent hepatitis C post-transplantation demonstrated $98 \%$ sensitivity and $84 \%$ specificity for LS using TE for predicting cirrhosis [28].

TE has also been used in assessing many other diffuse liver diseases, with good results, summarised in Wong and Chan [23].

TE has been studied for predicting complications of cirrhosis, such as portal hypertension and mortality. The AUROCs for predicting clinically significant portal hypertension (hepatic venous pressure gradient $\geq 12 \mathrm{mmHg}$ ), were $0.94-0.99$ for cut-offs ranging from 13.6 to $21 \mathrm{kPa}[29,30]$. For predicting grade 2 or 3 oesophageal varices, TE cut-off values from 19.8 to $47.5 \mathrm{kPa}$, with AUROCs of $0.72-0.78$ are proposed [31-33]. This wide spread in values makes TE inappropriate for selecting patients for endoscopy. More recent studies that investigated the possible role of measurements of TE in the spleen, performed with the assistance of conventional ultrasonography to select the measurement site, showed better correlation with portal pressure $(r=0.89)$ in patients with cirrhosis than liver assessment with TE [34]. Splenic assessment also produced high AUROC values (0.966) for the identification of patients with portal hypertension (hepatic venous pressure gradient $\geq 10 \mathrm{mmHg}$ ) [34], and TE seems to be more precise than Doppler ultrasound [35].

In a prospective study, 1457 patients with chronic hepatitis $C$ underwent liver biopsy, TE and serologic markers of fibrosis and were followed-up for 5 years; 77 patients died and 16 received liver transplantation. Patients with histological METAVIR F3 / F4 fibrosis had a significantly reduced 5-year survival as compared to those with F0-F2 fibrosis. The results for TE were more accurate than liver biopsy in predicting prognosis: those with TE $>9.5 \mathrm{kPa}$, had a significantly reduced 5-year survival [36].

Two prospective studies evaluating the risk of HCC development over three years in 866 hepatitis C virus [37] and 1130 hepatitis B virus patients [38] reported that the risk of developing HCC paralleled the increase of liver stiffness values, not only separating patients with or without cirrhosis, but also grouping patients in different risk classes within those with already established cirrhosis. TE has been tested to screen for subjects with significant fibrosis. In a study on 1190 subjects older than 45 from a general community-based population attending for a medical check-up, 89 (7.5\%) had LS measurements $>8 \mathrm{kPa}$. Though liver biochemistry was normal, a cause of chronic liver disease was found in $43 \%$ [39].

Intra- and inter-observer reproducibility of TE measurements are excellent (ICC 0.98 for both) in non-obese subjects [40]. TE values are higher in males.

\section{Practical points}

TE is performed with self-standing dedicated equipment with specific probes through an intercostal approach. It can therefore be used in numerous settings ranging from primary to tertiary care centers, outreach drug users facilities, jails and dispensaries. The examination procedure is standardized and a standardized reporting sheet, including all relevant information to judge on the quality of the examination, is available [41].

\section{Recommendations}

- TE can be used to assess the severity of liver fibrosis in patients with chronic viral hepatitis, provided that confounding factors are taken into account, and especially to distinguish patients with nil/mild fibrosis from those with significant fibrosis and to identify those with cirrhosis.

- TE is useful for assessement of liver fibrosis in patients with NAFLD, alcoholic liver diseases, and in patients co-infected with human immunodeficiency virus (HIV) and hepatitis C virus. Other types of chronic liver disease might also be investigated, but the evidence is more limited.

- TE is useful for assessement of liver fibrosis in patients with post-transplant recurrence of chronic hepatitis $C$.

- TE has some value for predicting the occurrence of complications of liver cirrhosis, portal hypertension, HCC and liverassociated mortality. It cannot replace upper gastrointestinal endoscopy for identifying patient with varices. 


\section{Pitfalls and limitations}

In a study on more than 13,000 LS measurements with the standard probe, failure occurred in $3.1 \%$ and results were unreliable in $15.8 \%$ of cases, both associated with BMI $>30 \mathrm{~kg} / \mathrm{m}^{2}$, age $>52$ years, and type 2 diabetes [3]. In another study, the technical failure rate with the standard probe correlated with the BMI; there was a failure rate of $7 \%$ for $\mathrm{BMI} \geq 30 \mathrm{~kg} / \mathrm{m}^{2}, 19 \%$ for $\mathrm{BMI} \geq 35 \mathrm{~kg} / \mathrm{m}^{2}$ and $59 \%$ for BMI $\geq 40 \mathrm{~kg} / \mathrm{m}^{2}$ [26]; however, the failure rate when using the XL-probe decreased to negligible levels $(0.7,0$, and $4.9 \%$, respectively) [26].

TE cannot be performed in patients with perihepatic ascites.

\section{Shear wave speed measurement}

Shear wave speed measurement elastography is available on several systems (see Part 1 for details [1]).

\section{Clinical applications}

As with TE, Acoustic Radiation Force Impulse (ARFI) shear wave speed quantification was at first used and validated in patients with chronic hepatitis C. Cut-offs of $1.21-1.34 \mathrm{~m} / \mathrm{s}$ predict significant fibrosis $(F \geq 2)$, (AUROC $0.85-0.89$ ) [42, 43], while for cirrhosis, ARFI cut-offs range between 1.55 and $2 \mathrm{~m} / \mathrm{s}$ (AUROC $0.89-0.93)$ [42-44]. The accuracy of ARFI for the assessment of liver fibrosis is similar to TE $[42,45,46]$. ARFI shows promising results in patients with NAFLD and NASH $[47,48]$ and post-transplantation [49].

In a recent meta-analysis by Friedrich-Rust et al. of 518 patients with chronic liver disease [50], the AUROC was 0.87 for predicting significant fibrosis $(\mathrm{F} \geq 2), 0.91$ for severe fibrosis $(\mathrm{F} \geq 3)$ and 0.93 for cirrhosis. Interobserver variability was reported to be good in healthy subjects [16] and in patients with chronic liver disease (ICC $=0.87$ ) [15] when measurements are taken appropriately in the right lobe. ARFI allows measurements at different sites and a comparison of the two lobes of the liver showed a trend toward higher values on the left $[14,15,51]$. However, results on the right were more accurate compared to conventional percutaneous liver biopsy [51].

2D-SWE using the Aixplorer ${ }^{\circledR}$ system is reported in two studies in 133 and 121 patients with chronic hepatitis C (with 29\% and $100 \%$ of patients having biopsy as gold standard) $[52,53]$. The AUROCs were similar in the two studies $(0.95$ and 0.98 for $\mathrm{F} \geq 2$, 0.96 and 0.96 for $\mathrm{F} \geq 3,0.97$ and 0.98 for $\mathrm{F}=4$ respectively in the French and Italian studies) and better than those for TE, also performed in all patients. Interoperator and day-by-day intraoperator reproducibility are good in healthy subjects [54].

\section{Practical points}

The patient should be fasted. Shear wave speed measurements are performed intercostally in the right liver with conventional curved arrays. The probe is aligned along an intercostal space. In 2D-SWE, if the signal is weak or unstable, the penetration mode can be activated and pressure can be applied to open the intercostal space - contrary to the general recommendation, this does not increase the liver's stiffness as the intervening tissues prevent distortion of the liver surface. Once the 2D-SWE signal has stabilized (after 3 to 4 seconds), an image can be acquired and LS can be measured using an elasticity box which should be paced to avoid the superficial parts of the liver and discrete structures in the liver. The recommended depth is between 3 and $7 \mathrm{~cm}$.

\section{Recommendations}

- pSWE and 2D-SWE can be used to assess the severity of liver fibrosis in patients with chronic viral hepatitis, especially with hepatitis $C$. The weight of evidence that is available varies between different shear wave methodologies and for different brands of scanners using the same methodology.

- pSWE with ARFI is promising for liver fibrosis assessment in patients with NAFLD, and post-transplant patients.

\section{Pitfalls and limitations}

As with TE, elevated aminotransferase levels are associated with higher LS values on ARFI [55, 56]; whether this is true also for 2D-SWE is not yet known but, since these enzyme flares probably reflect liver inflammation, it would be expected to be a general effect.

Little information is still available about the performance of pSWE, and particularly of 2D-SWE in non-viral chronic liver disease.

Better correlation of ARFI LS measurements with histological liver fibrosis has been reported when using quality indicators: interquartile range $<30 \%$ and success rate $>60 \%$ [57]. Shear wave methods (pSWE and 2D-SWE) can be utilized in patients with ascites.

\section{Strain elastography}

All the major manufacturers have strain elastography incorporated at least in their high-end systems but only one, Hitachi, has been widely used for the liver. Results from this system therefore are the main focus of this section, but this should not be taken to imply that others are not recommended: it merely reflects current experience.

\section{Clinical applications}

Different scores for semi-quantitative interpretation of strain elastography have been proposed: the German Elasticity Score [58], the Japanese Elasticity Score [59] and the Liver Fibrosis Index (LF Index) [60]. All are based on visual assessments of the spatial patterns of strain imaging within the ROI. However, the evidence with this approach is still too limited to allow recommendation for its clinical use, at least in European patients.

\section{Elastography for focal liver lesions}

Elastography (strain elastography, 2D-SWE, pSWE) have been studied recently to characterise focal liver lesions, to differentiate between benign and malignant masses [61-64]. Promising results were reported, but more research is needed, especially in comparison to CEUS, before recommendations on its use in clinical practice can be made. At present, elastography cannot be recommended for distinguishing benign from malignant liver lesions.

\section{Breast \\ $\nabla$}

\section{Background}

In the breast, elastography has found application in focal diseases, relying on the known high stiffness of most cancers compared with both the normal breast and with benign lesions. Both strain and shear wave methods have been evaluated and the main thrust has been to improve the differentiation between breast imaging reporting system (BI-RADS) 3 lesions (which need follow-up) and to a lesser extent to improve the management of BI-RADS 4a lesions by reclassifying them as 3 or $4 \mathrm{~b}$. 


\section{Strain elastography}

Strain elastography is initially based on visual inspection of the stiffness map using the Tsukuba criteria in which the amount of stiff tissue in and around the lesion is assessed [65]. This five-point scale scores the lesion according to the extent of stiff tissue relative to the background, with a score of 1 for a lesion not stiffer than surrounding tissue, 2 and 3 to lesions with increasing proportions that are stiffer and 4 given to a lesion that is stiffer throughout; 5 indicates that the stiffness extends beyond the margins of the mass seen on B-mode.

The best cut-off point for discriminating benign from malignant masses falls at the $3-4$ boundary and the addition of elastography to B-mode evaluation has been shown to improve the accuracy of BI-RADS classification [66-68]. In practice, the elastogram with strain elastography takes up to a few seconds to settle to a reproducible image. Most systems offer a quality estimator. A sequence stored in the cine loop should be reviewed slowly and the most reproducible frame(s) selected. Regions of interest can then be placed to cover the whole lesion and in the adjacent fat (ideally at the same depth) to allow calculation of the fat/lesion ratio.

A series of 370 consecutive patients with breast lesions smaller than $2 \mathrm{~cm}$ (39\% malignant) were studied with strain elastography using histology as the reference. The B-mode BI-RADS accuracy was improved, with sensitivity and specificity changing from $90.3 \%$ and $68.3 \%$ to $83.9 \%$ and $87.8 \%$ respectively by the addition of elastography [69]. In a series of 193 lesions and using the 3:4 cut-off, Schaefer et al. found that the sensitivity was $96.9 \%$, and the specificity was $76 \%$ and recommended that strain elastography could be used as a complement to B-mode scoring but not alone, mainly because there were two cancers with Tsukuba score of 1 [70]. In a study of 200 histologically proven lesions (116 malignant), Fischer et al. found that the strain ratio was more sensitive and specific than either B-mode ultrasound or mammography, with values of $95 \%$ and $74 \%$ respectively when using a lesion/fat cut-off ratio of 2.27 [71].

An important feature is that cancers appear larger on the elasticity image than on B-mode $[65,72,73]$. This may result from local invasion by the cancer that is not always obvious on B-mode. The elastographic size correlates better with the actual size of the cancer at surgery and an elastography:grey scale width ratio above 1 had an overall sensitivity of $98.6 \%$ and an overall specificity of $87.4 \%$ in a multicentre series of 578 patients with biopsy proof [74]. The quantification of elastography using strain and width ratios can increase sensitivity at the expense of specificity.

Two recent meta-analyses on strain imaging have been reported. In the analysis by Gong et al. [75] 212 English language papers were found and 23 were suitable for detailed analysis. Most used the 5-point Tsukuba scale. The overall mean sensitivity and specificity for the diagnosis of malignant breast lesions were 0.83 (95\% CI, $0.814-0.853)$ and $0.84(95 \% \mathrm{CI}, 0.829-0.854)$ with a summary ROC of 0.93. The analysis by Sadigh et al. [76] identified over 3000 citations of which 12 were suitable for further analysis, including over 2000 breast lesions. Both the strain ratio and the relative size (length ratio) were evaluated. The cut-off point for strain ratio varied from 4.5 to 0.5 in different studies. Summary test operator sensitivity was $88 \%$ (95\% credible interval [CrI], $84-91 \%$ ), and specificity was $83 \%$ (CrI, $78-88 \%$ ) for strain ratio and $98 \%$ (CrI $93-99 \%$ ) and $72 \%$ (CrI $31-96 \%$ ) for length ratio.

The elastographic appearance of breast cysts depends on the techniques used [2, 77-79], but whatever the technique SE appears to be accurate in establishing that the content is liquid.

\section{Shear Wave Elastography (2D-SWE)}

The colour (or optionally a grey-scale) overlay indicates the shear wave speed (or the converted $\mathrm{kPa}$ values) and ROIs can be placed on the stiffest part of a lesion and on adjacent fat to obtain quantitative read outs as well as ratios. Cancers tend to be stiff and also more heterogeneous than benign lesions and often the stiffness seems to be most marked at and around the periphery of the mass.

When the elasticity cannot be estimated, the colour display is switched off so that the underlying B-mode image (usually black) is revealed [1]. This should not be mistaken for a low value that signifies a soft region. Reasons for the absence of shear wave signals include situations where the system cannot measure the stiffness because the tissue is not vibrated enough and when the amplitude of the shear wave is too low and is lost in noise [80]. Biological conditions where the shear wave cannot be imaged are also encountered, such as when the speed of the shear wave speed is too high to be captured, (e.g. in extremely stiff cancers), and when the interrogating beam cannot penetrate, e.g. in regions that are shadowed-out, typically in the deeper parts of scirrhous cancers [1]. A practical rule is that the stiffest part of the mass or surroundings is definitive. As with strain elastography, genuinely soft cancers do occur, albeit rarely: these appear as soft masses rather than as a void in the colour layer.

Cysts deserve special mention: non-viscous fluids do not support shear waves and so they appear as colour voids, usually seen as black regions where the anechoic B-mode layer shows. However, when the fluid is viscous, shear wave signals may be seen as soft regions.

A series of report on the impact of 2D-SWE on the classification of breast masses [81, 82], including a large prospective study of around 1000 patients [83], testify to its value in reclassifying BIRADS 3 and 4a masses. In this study, reclassifying BI-RADS 3 lesions as $4 \mathrm{a}$ and thus precipitating biopsy while reclassifying BIRADS 4a masses as 3 and thus avoiding biopsy, would have improved specificity over conventional ultrasound from $61.1 \%$ to $78.5 \%$ without impairing sensitivity in 650 lesions. This was achieved by using a cut-off value of maximum shear wave speed of $5 \mathrm{~m} / \mathrm{s}(80 \mathrm{kPa})$.

The same study also included an analysis of reproducibility, which was very high. Intraclass correlation for 2D-SWE diameter was almost perfect $(\mathrm{ICC} \geq 0.94)$. Intraobserver reliability for maximum and mean elasticity were almost perfect $(\mathrm{ICC}=0.84$ and 0.87$)$ and substantial for ratio of lesion-to-fat elasticity $(I C C=0.77)$. Interobserver agreement was moderate for 2D-SWE homogeneity $(K=0.57)$, substantial for qualitative colour assessment of maximum elasticity ( $(k=0.66)$, fair for B-mode mass margins $(k=0.38)$, and moderate for B-mode mass shape $(\mathrm{k}=0.58)$, orientation $(k=0.53)$, and BI-RADS assessment $(k=0.59)$ [84].

Additional 2D-SWE features support the potential to downgrade BI-RADS 3 lesions, as described by the BE-1 study group [85]. These results indicate that 2D-SWE can complement conventional US to improve diagnostic performance by reducing unnecessary initial short-term follow-up of BI-RADS 3 breast lesions, when the 2D-SWE findings are benign, especially when maximal elasticity is $\leq 20 \mathrm{kPa}$.

Quantitative SWE with ARFI can be used for characterising breast masses. In a series of 161 masses with 43 malignancies, using a shear wave speed cut off of $3.6 \mathrm{~m} / \mathrm{s}$, a sensitivity of $91 \%$ and a specificity of $80.6 \%$ were achieved [86]. 


\section{Practical points}

No particular patient preparation is required and the elastography estimate is a seamless part of the standard examination. The patient is examined in the standard position with the appropriate arm elevated. Conventional linear arrays are utilized, as for standard grey scale examinations.

Elasticity box: placement and sizing of the box is important. It should cover the lesion together with sufficient surrounding breast tissue to allow comparison between the two regions. Elastography works best when the lesion is surrounded by breast tissue. If it lies close to the skin or the rib cage, the results may be unreliable. Similarly, lesions larger than the ultrasound fieldof-view may give unreliable results and in this case, comparisons with the surrounding fat are impossible. Briefly, lesions that are too large or too deep may not allow good quality elastograms to be obtained [87].

The main use of elastography in the breast is as an adjunct to conventional ultrasound to improve the differentiation between benign and malignant lesions and several studies attest to the value of strain elastography in refining the BI-RADS score $[76,88,89]$. The technique is easy to learn and reproducibility is better than with B-mode US.

The addition of elastography to conventional ultrasound assessment of breast masses is endorsed in the forthcoming ACR BI-RADS Ultrasound lexicon (personal communication, EB Mendelson, 2012) and can be recommended provided the user has adequate experience with the system being used. Elastography should be used as an adjunct to conventional high quality ultrasound and it fits smoothly into the standard examination protocol. Clinical concern over missing any cancer suggests that it should not be relied upon on its own to downgrade a lesion that would otherwise be sent for biopsy (BI-RADS 4a or higher) but that it can help by upgrading a mass of low suspicion that would otherwise be followed-up (BI-RADS 3), and thus sent for biopsy. In practice, users find that such changes in management are uncommon and elastography is more usually used to increase confidence when the findings concur with the standard ultrasound findings. It is also useful for confirming that a lesion is a cyst when the contents are echogenic.

\section{Limitations and artefacts}

The pattern of cysts has been mentioned; this may be considered as an useful artefact since they highlight the cystic nature of the lesion [79].

Not all cancers are stiff and not all stiff lesions are cancers, so regarding elastography as a tool that provides clear cut-off values is unsafe. In vitro measurements of the stiffness of breast masses show overlap, with a few fibroadenomas that are stiff and some soft cancers [90, 91]. Fibrous tissue is often surprisingly soft but sometimes is stiff. The elastographic findings should be considered as an associate feature of conventional ultrasound and considering clinical background.

Pre-stress with the probe should be avoided as this increases the stiffness of all tissues.

In SWE, a failure to capture the shear wave may occur [80]. Care must be taken to distinguish absence of the colour layer from the colours that indicate a low shear wave speed. The appearance of cysts containing viscous fluid that may give signals has also been mentioned. The push pulses sometimes "breakthrough" and produce spaced vertical bands, most marked near the skin. They are obviously artefacts and should not cause diagnostic confusion.

\section{Recommendations for all forms of elastography}

- To increase diagnostic confidence in the benign or malignant nature of a lesion.

- To re-grade benign-appearing lesions that are stiff and consider them for biopsy.

\section{Thyroid \\ $\nabla$}

\section{Background}

Thyroid nodules are frequently detected with ultrasound and are especially common in parts of the world with a poor iodine supply [92]. Conventional ultrasonography is very sensitive to thyroid nodules but cannot reliably differentiate the few that are malignant from the very common benign nodules [93, 94].

\section{Methods}

A classical feature of malignancy is a hard or firm consistency upon palpation. However, this assessment is subjective and depends on the experience of the examiner. Small and deep nodules and those in a multinodular goitre cannot be palpated reliably. With the introduction of elastography, reproducible assessment of tissue consistency has become available.

Both strain and shear wave elastography methods have been used in the thyroid.

For strain elastography, classifications using 4 or 5 visual categorical scores, either colour-coded or in grey-scale have been proposed. The best evaluated differentiates between completely or predominantly soft nodules as a benign sign and a completely or predominantly hard nodule as a sign of malignancy [95]. The strain ratio between a lesion and adjacent healthy thyroid tissue has also been proposed to differentiate benign from malignant lesions [96].

Two quantitative shear wave elastography methods have been evaluated to date: pSWE and 2D-SWE.

\section{Clinical applications}

Strain elastography

Most published studies have used strain elastography. A recent meta-analysis including 639 nodules reported a mean sensitivity of $92 \%$ and a specificity of $90 \%$ for the diagnosis of malignant thyroid nodules [97]. However, the patient population was highly selected with a $24 \%$ prevalence of malignancy and many patients were sent to surgery, which, though good as a standard, does not reflect typical clinical practice. In addition, the results were challenged by a recent study that reports no additional value of strain elastography to experienced B-mode ultrasound [98].

Two recent studies [96, 99] with 309 and 97 patients respectively, used strain values and ratios to determine thyroid nodule stiffness. All patients were referred to surgery. Vorlander et al. utilized a proprietary absolute measurement of strain value, which ranged from 1.0 (max soft) to 0.1 (max hard) and reported a negative predictive value (NPV) for malignancy of $100 \%$ using a strain ratio cut-off of $>0.31$ and a positive predictive value (PPV) of $42 \%$ using a cut-off of $<0.15$ [96]. Cantisani et al. reported a sensitivity, specificity, PPV and NPV of $97.3 \%, 91.7 \%, 87.8 \%$ and $98.2 \%$ for the prediction of malignancy using a strain ratio $\geq 2$ (ratio of lesion strain to surrounding parenchyma). Elastography was more sensitive and specific than all conventional ultrasound features.

Another study compared strain elastography based on four point scores and the strain ratios between the nodule and the surround- 
ing thyroid at the same depth [100]. The diagnostic accuracy of the strain ratio evaluation was slightly higher $(0.88$ vs. $0.79, \mathrm{p}<0.001)$ than that of the elastography score, with a higher specificity. Another prospective study [101] evaluated strain elastography in 51 patients with small single solid nodules of $3-10 \mathrm{~mm}$ submitted to surgical resection. A five-point scale based on that developed for the breast was used [65]; with a cut-off at 3/4, a sensitivity of $91 \%$, specificity of $89 \%$, PPV $94 \%$ and NPV $85 \%$ for the diagnosis of malignant nodules was found. Thus, strain elastography seems to have a potential even in small nodules.

However, additional studies, including only a few follicular carcinomas, revealed inconclusive data on the value of elastography. Most malignant nodules missed by elastography were follicular carcinomas which can be soft and difficult to differentiate from benign nodules [97]. Strain elastography was evaluated in 102 patients with indeterminate cytology who went to surgery [102]. Histology revealed 64 follicular adenomas, 32 follicular variants of papillary thyroid cancer, 4 follicular carcinomas and two hyperplastic nodules. In this selected population, strain elastography (4-point scale) only reached a PPV of $34 \%$ and a NPV of $50 \%$. Conversely, Cantisani et al [103] reported a study including 140 nodules with indeterminate cytology in which elastography with a strain ratio $>2.05$ achieved sensitivity, specificity, NPV, PPV and accuracy of $87.5 \%, 92 \%, 94.8 \%, 81.4 \%, 89.8 \%$, respectively.

\section{Shear wave elastography (pSWE and 2D-SWE)}

Shear wave speed is reported to be higher in malignant nodules than benign nodules in three studies using 2D-SWE, mainly investigating patients submitted to surgery [104-106] so that accuracy values in a more typical population remain to be confirmed.

ARFI with point shear wave speed quantification (pSWE) was evaluated and compared to strain elastography in two studies $[107,108]$. As with strain elastography, malignant lesions were significantly stiffer than benign lesions. One of these studies compared diagnostic accuracy of strain elastography using a 4-point visual scale and pSWE shear wave speed measurement and showed no statistically significant difference between the two methods (AUROC for the diagnosis of malignancy 0.74 for SE and 0.69 for pSWE, $\mathrm{p}=\mathrm{ns}$ ) [107].

Elastography might be useful in multinodular goitre to select nodules for fine needle aspiration biopsy, but there is no data available at present.

\section{Practical points}

Elastography of thyroid lesions can be performed using either SE or SWE with many high-end systems using linear transducers. No patient preparation is required.

\section{Recommendations}

- Elastography is an additional tool for thyroid lesion differentiation.

- Based on expert opinion, elastography may be used to guide follow up of lesions negative for malignancy at FNA.

\section{Limitations}

Intralesional calcifications are common and may bias the stiffness of the lesion, as has been shown for peripheral calcifications [109-111].

Strain elastography should be interpreted with caution in extensive cystic areas since this may cause artefacts.
Elastography shows high sensitivity, specificity and NPV for the diagnosis of papillary carcinoma: however, the evaluations were performed in highly specialised centres with high incidences of carcinoma.

\section{Gastrointestinal tract}

$\nabla$

\section{Introduction}

B-mode US of the layered structure of the gastrointestinal (GI) wall usually shows five distinct layers [112]. Elastography may also show the layered structure of the GI wall, but these do not always correspond to the B-mode layers. A special method, Strain Rate Imaging (SRI), which shows the sign of the strain, is used to assess contractility of the GI walls [113]. Furthermore, strain elastography is used to assess the hardness of focal lesions of the GI tract.

\section{Gastrointestinal wall pathology}

A major clinical challenge in Crohn's disease is to evaluate whether a stenosis is caused by inflammation or fibrosis, since the latter requires surgical intervention while an inflammatory stricture requires medical treatment. Strain elastography has been tested in this setting and helps the distinction between these two conditions, since fibrotic stenoses appear stiff and inflammatory stenoses soft [114]. Furthermore, patients with active Crohn's disease have a higher strain ratio between the inflamed and normal regions than patients in remission [115] and than patients with active ulcerative colitis. In a study on inflammatory bowel disease, the findings on elastography were significantly correlated with the endoscopic findings [116].

\section{Gastrointestinal motility}

Gastric contractions and peristaltic waves can be visualised and monitored by ultrasonography and the method is sometimes used in patients with dyspepsia $[117,118]$. Assessment of the relative strain of the muscle layers of the gastric wall is feasible and allows detailed mapping of strain distribution [113, 119] and SRI can distinguish the contractile activity of the longitudinal from the circular muscle layers that cannot be appreciated on B-mode. SRI has been evaluated in vitro [120, 121] and in vivo to monitor response to drug intervention [122]). In patients with functional dyspepsia, SRI demonstrated that subgroups of dyspepsia could be selected on the basis of strain measurements of the gastric wall [118].

\section{Practical points}

Strain imaging of the GI tract is normally performed with linear transducers. SE can be performed with many high-end ultrasound scanners. Conversely, SRI is only available with specifically dedicated software currently provided by one manufacturer.

\section{Limitations}

Shadowing by bowel gas precludes a complete overview of all bowel segments using transabdominal ultrasound. Peristalsis poses a major challenge to strain imaging of the bowel; it impairs image quality and reduces the accuracy of semi-quantitative elastographic measurements. More studies are needed to establish the role of strain imaging in the evaluation of GI pathology and motility. 


\section{Recommended uses and indications}

Elastography is indicated for:

- Characterising bowel wall lesions and possibly discerning the active phase of inflammation from fibrotic stenosis using strain elastography.

- Evaluation of gastric contractility and GI wall strain using SRI.

\section{Endoscopic ultrasound (EUS) elastography}

\section{Introduction}

EUS elastography is a method for the in vivo characterisation of hardness of pancreatic lesions [123-125], lymph nodes [126, 127] and gastrointestinal wall layers (especially in the anorectum [128]). Though the technology needs further refinement, initial reports demonstrate proof-of-principle for the evaluation and staging of subepithelial and epithelial gastrointestinal tumours; however, its clinical significance is not yet established [129, 130].

\section{Methods}

Only strain elastography is currently available and it can be used with longitudinal and radial echo-endoscopes, the former having the advantage that suspicious regions can be biopsied under direct visualisation. The area to be evaluated is defined by a ROI in a similar way to colour Doppler. The necessary pressure can be applied by manipulating the probe, though very little additional pressure is required as the forces from the pulsation of adjacent vessels are usually sufficient. The elasticity box must be sufficiently large to encompass the lesion and enough surrounding normal tissue for comparison, ideally containing equal amounts of each. Comparing two different tissues within the elasticity box (e.g. a focal pancreatic lesion and adjacent pancreatic parenchyma) allows calculation of the strain ratio [131]. New technical developments allow for averaging over several frames to calculate the mean histogram value, which corresponds to overall strain within a selected area in the elasticity box [132, 133].

\section{Interpretation}

Strain elastography allows assessment and visualization of relative stiffness differences [1]. Interobserver reliability was substantial for qualitative elastographic characterization of solid pancreatic lesions (kappa values $0.72-0.785$ ) [123, 124, 134]. More conflicting results were obtained for lymph nodes: in one study, interobserver agreement proved to be moderate for general elastographic impression and for strain ratio (kappa 0.58 and 0.59 , respectively), but not for a defined scoring system (kappa 0.35) [135]. A multicentre study, however, reported substantial interobserver agreement with this scoring system (kappa 0.66) [123].

\section{Limitations and artefacts}

A number of technical factors specific for EUS may adversely influence elastographic assessment in clinical practice. The small size and penetration depth of EUS transducers limits the applicability of endoscopic ultrasound elastography for characterising large and deep-seated lesions. If the ROI is too small to adequately represent the tissue surrounding the lesion or if there is size discrepancy between the lesion and the surrounding tissue, assessment of relative stiffness differences between the lesion and surrounding normal tissue may be impaired [124]. Moreover, the reproducibility of elastography may be reduced in several anatomical sites in which the effects of physiological movement are too weak or too strong (heart, large arterial vessels) or in which compression with the transducer is difficult (left adrenal gland, spleen, or parts of the liver). Interposition of large vessels, cystic lesions and dilated ducts between the target lesion and the transducer may impair strain assessments.

The utility of EUS elastography for discrimination of malignant lesions or infiltrations from benign disease may be hampered by tumor necrosis (which is soft), by fibrosis (e.g. of lymph nodes pancreatitis, and by mucinous or semi-solid content of cystic lesions [123].

\section{Clinical applications \\ Pancreas}

Anatomical considerations and image interpretation

The pancreas is of uniform intermediate stiffness but, with advancing age, it may become heterogeneous. Embryologically the pancreas develops from two primordia, the dorsal and ventral anlages. The latter can be hypoechoic and may be confused with focal inflammation or a tumour. Elastography has proven to be particularly helpful because the tissue properties are similar in the two parts of a healthy pancreas [136].

\section{Practical advice}

The elastography patterns have been described in healthy subjects $(n=20)$, in diffuse chronic pancreatitis $(n=20)$ and in focal pancreatic lesions $(n=33)$ [126]. All malignant pancreatic tumours and serous cystadenomas showed a honeycomb pattern of mid hardness, and were well delineated against healthy parenchyma. However, this pattern was also observed in half of the chronic pancreatitis patients, so that the specificity of the method in this study was only about $60 \%$. The reason for this is the similar fibrotic structure producing similar mechanical properties in cancer and chronic pancreatitis [126].

In acute pancreatitis, necrosis appears as softer tissue compared to tumours. Whether elastography can help in the diagnosis of pancreatic fibrosis remains to be evaluated. Elastography does not contribute to the early diagnosis of pancreatic carcinoma in chronic pancreatitis $[123,137]$.

EUS Elastography is helpful in diagnosis of early autoimmune pancreatitis due to the unique appearance of universal stiff tissue in this disease [137].

For the differential diagnosis of benign and malignant focal pancreatic masses, qualitative $[123,126]$ and semi-quantitative SE approaches $[125,133,134,138,139]$ have been used, both showing high overall accuracy. Two multicentre studies showed a high sensitivity (over $90 \%$ ), but lower specificity and negative predictive value for the diagnosis of benign versus malignant focal pancreatic masses $[124,134]$. Two meta-analyses published recently have indicated excellent values of EUS elastography for differentiation of focal pancreatic masses, with high sensitivity but lower specificity $[140,141]$

Computer-aided diagnosis techniques might improve the accuracy for the differential diagnosis of focal pancreatic masses, the most used being artificial neural networks [125, 133]. However, there is expert consensus and evidence in the literature that strain elastography cannot replace cytopathological diagnosis of focal pancreatic disease at present, mainly because of its limited specificity. However, when EUS-FNA is negative, a suspicious finding on elastography can influence further clinical decisions. Recent observations suggest that percutaneous elastography (ARFI) may be used in differentiation of pancreatic lesions [142]. 


\section{Recommendations}

- EUS elastography is useful as a complementary tool for the characterisation of focal pancreatic lesions.

- When there is strong clinical suspicion of pancreatic cancer, but the biopsy is inconclusive or negative, a hard focal lesion on elastography and/or suggestive endoscopic CEUS (hypovascular lesion) [143] should guide clinical management by indicating repeat EUS-FNA or direct referral to surgery.

- EUS elastography cannot be currently recommended for differentiating advanced chronic pancreatitis from pancreatic carcinoma due to their similar tissue stiffness in a large proportion of cases.

\section{Lymph nodes}

Reliable classification of benign and malignant lymph nodes is important for prognosis and selection of appropriate therapy for many cancers, e.g. oesophageal, stomach, bronchial, and pancreatic [144]. Endosonographic B-mode for detecting malignant lymph nodes varies in accuracy between $50-100 \%$ [145]. Strain elastography has the potential to add value to B-mode US, particularly by better targeting lymph nodes or nodal invasion for biopsy $[124,130,132,146]$. A meta-analysis calculated a sensitivity of $88 \%$ and a specificity of $85 \%$ of EUS elastography for differentiating between benign and malignant lymph nodes [147]. Nevertheless, a recent study with pathological confirmation for each lymph node yielded lower values of sensitivity (55-59\%), with a better specificity ( $82-85 \%$ ) compared with the performance of standard EUS criteria [127].

\section{Recommendations}

- Complementing established B-mode criteria EUS strain elastography is useful as an additional tool for discrimination of benign and malignant lymph nodes.

- EUS elastography may be used for identifying the most suspicious lymph node and/or harder lymph node regions suspicious for malignant invasion that should be targeted for EUS fine needle aspiration biopsy.

\section{Prostate \\ $\nabla$}

\section{Introduction}

The screening standard for prostate abnormalities has been the combination of digital rectal examination and the serum prostate specific antigen (PSA) level. However, PSA screening leads to a substantial number of unnecessary biopsies in patients with no or indolent cancer who do not need immediate treatment [148] and has a high false negative rate (17-21\%) [149]. Saturation biopsy (up to 40) can rule out prostate cancer, but has many limitations, including cost and morbidity, and over-diagnosis of microscopic tumor foci [150].

Two different prostate transrectal ultrasound approaches can be used to identify stiff prostate tissue: strain and shear wave elastography, as described in part 1 [1].

\section{Strain elastography}

Hypoechoic stiff lesions of the prostate are suspicious for malignancy [151]. Slight compressions are induced using the transrectal probe. The use of an inflatable balloon has been suggested to improve standardization of compression applications. The quality index helps ensure appropriate speed and pressure. The elastography box should cover the entire gland and the sur- rounding tissues, but avoid the bladder. Semi-quantitative information can be derived by measuring the strain ratio between two regions of interest (usually one considered as normal and the other abnormal).

By stepwise scanning of the prostate from base to apex, strain elastography allows detection of stiff regions, and provides stiffness comparisons between lesions and the adjacent prostate tissue. Most studies report a significant improvement in prostate cancer identification with strain elastography, including guidance for targeted biopsies [152-155]. However, there are still some controversies and one recent study reported its inability to differentiate prostate cancer from chronic prostatitis [156]. The sensitivity, specificity, negative predictive value, positive predictive value, and accuracy for identifying cancer indexlesions for focal therapy were $58.8 \%, 43.3 \%, 54.1 \%, 48.1 \%$, and $51.6 \%$, respectively [157]. Though improvement in biopsy guidance is reported in many studies $[155,158,159]$, others did not confirm this result [160].

\section{Shear-wave elastography}

Unlike strain elastography, SWE requires no compression on the rectal wall [161]. Optimised settings include maximising penetration and setting up an appropriate scale. As of 2012, only 2DSWE with Aixplorer system is available for transrectal shear wave speed measurement. The image can cover half the gland in transverse section, so each side of the prostate is scanned separately from base to apex for review and measurements of elastography values. For each plane, the transducer is maintained in a steady position until the image stabilises. Hypoechoic stiff lesions are suspicious for malignancy. The ratio between the mean elasticity values of two regions can be calculated.

In young healthy subjects the entire prostate exhibits a uniform soft appearance with low stiffness values $[162,163]$. In benign prostate hyperplasia, the peripheral zone remains soft and homogeneous, while the central and transition zones become heterogeneous and hard, particularly when there are calcifications. Typical benign peripheral lesions are as soft as the surrounding normal parenchyma, while cancers are stiffer $[162,163]$. The best cut-off stiffness value to maximize the negative predictive value for malignant lesions was found to be 35 and $37 \mathrm{kPa}$ in two studies with 2D-SWE [159, 160], providing the best performance of with sensitivity, specificity, PPV and NPV of $63 \%, 91 \%, 69.4 \%$, and $91 \%$. The SWE ratio provided more discriminatory values as it takes into account the increased stiffness of the peripheral zone from calcification and chronic prostatitis. The best ratio between the nodule and the adjacent peripheral gland for benign and malignant lesions was $1.5 \pm 0.9$ and $4.0 \pm 1.9$ respectively $(\mathrm{p}<0.002)$ [162].

\section{Practical advice}

No specific patient preparation is required for either technique. Elastography imaging is conducted after conventional prostate transrectal ultrasound examination.

\section{Clinical potential}

Several studies indicate that elastography provides useful additional information to conventional transrectal ultrasound for prostate cancer detection. Applications that have been more extensively investigated include characterisation of abnormal areas, detection of lesions not seen with any previous imaging technique and biopsy targeting. 


\section{Practical points}

Transrectal Ultrasound Elastography USE is performed with endocavitary probes using a variety of configurations for 2D-SWE or SE.

\section{Limitations and artefacts}

Both techniques suffer from intrinsic limitations: not all cancers are stiff and not all stiff lesions are cancers (particularly in the presence of calcifications and fibrosis). The transrectal technique carries an intrinsic risk of inadvertently applying excess precompression because of the end-fire arrangement of the transducer.

Limitations of strain elastography include the non-uniform force over the gland, intra- and inter-operator dependency.

2D-SWE has additional limitations such as a slower frame rate and the small elasticity box which only allows interrogation of half the gland at a time.

\section{Recommendations}

- To identify suspicious target regions for biopsy and increase the positive biopsy rate.

\section{Musculoskeletal \\ v}

\section{Background}

Disease alters the biomechanical properties of muscles and tendons. US elastography has been employed for research in biomechanics of the musculoskeletal system since the early $90 \mathrm{~s}$ [164], however, the technique has only recently been applied in clinical practice.

\section{Methods}

Both strain and SWE elastography can be used to assess musculotendinous structures, but most of the available evidence refers to the use of strain elastography $[165,166]$.

\section{Clinical applications}

The Achilles tendon has been the most studied musculoskeletal structure with strain elastography. Based on three prospective studies examining 50,80 and 25 asymptomatic subjects using strain elastography, the Achilles tendons are usually hard (87$93 \%$ ) or may contain soft areas or stripes parallel to the long axis of the tendon, [167-169]. Alterations in strain elastograms of asymptomatic Achilles tendons mainly occur in the mid-portion, they do not always correspond to changes on conventional US and their nature is not yet clarified: they may correspond to early abnormalities or be false positive findings [167 - 169]. The reproducibility of strain elastography for the normal Achilles tendon has been found to be good to excellent using a qualitative twoor three-level scale $[167,168]$ and poor (variation 29-37\%) using semi-quantitative measurements (strain ratio) [167]. In symptomatic chronic Achilles tendinopathy, the tendons usually contain large, well-delineated soft regions, corresponding to areas of mucoid degeneration and partial ruptures, whereas in surgically repaired Achilles tendon ruptures, regions of increased stiffness may be a consequence of tendon healing $[168,169]$. The overall correlation between US and strain elastography findings in symptomatic Achilles tendinopathy has been reported to be good [168, 169]. The clinical value of method in managing patients with tendinopathy has not yet been examined. However, in a recent cadaveric study, elastography detected histologically verified tendon degeneration in all 14 Achilles tendon segments, whereas B-mode ultrasound could detect only $85.7 \%$, suggesting that elastography might be able to detect signs of histopathological degeneration of Achilles tendinosis more sensitively than B-mode [172]. There is no published data on the clinical use of shear wave elastography for the Achilles tendon.

Strain elastography of normal relaxed muscle shows an inhomogeneous pattern of intermediate or high stiffness with a few scattered soft areas mainly around muscle borders $[173,174]$.

The clinical value of strain elastography in muscle spasticity has been evaluated in three studies including small numbers of patients with cerebral spasticity (7,15 and 17 patients). The studies showed that the combination of strain elastography with clinical scale assessments can diagnose muscle stiffness changes and monitor the effect of rehabilitation therapy [174-176].

\section{Recommendations}

- Strain elastography can be used as a supplementary tool to conventional US scanning to increase the diagnostic confidence in diagnosing Achilles tendinopathy.

- Strain elastography can be used to depict stiffness changes in congenital muscle spasticity.

\section{Practical points}

To minimize intra-observer variation and avoid transient temporal fluctuations in the Achilles tendon, the scoring or the measurements should be based on examination of entire cine-loops rather than on single static images. It is recommended to store several (at least 3) compression-relaxation cycles and then select the best elastograms for evaluation. The probe should be perpendicular to the tissue to avoid anisotropy, as the B-mode appearance influences the quality of the elastograms. Overlapping images should be acquired when examining the length of the Achilles tendon, to allow for stiffness artefacts at the ends of each elastogram.

In the cases of the Achilles tendon, where there is little overlying subcutaneous fat, and when a minimum depth from the skin is needed to place the ROI, gel pads or probe adaptors can be employed. The use of stand-off devices for strain elastography of the Achilles tendon has been shown not to influence the elastogram [171], as opposed to the inclusion of gel within the ROI, which should be avoided, as it increases the scatter of the relative stiffness values and may mask minimal differences in tendon stiffness [165].

\section{Artefacts}

Artefacts encountered in strain elastography of the muscles and tendons include fluctuant changes within the Achilles tendon and at muscle borders, possibly due to stress and strain concentration between tendon fibres as well as at the borders the Achilles tendon in axial elastograms because of varying contact with the skin.

\section{Future perspectives}

\section{$\nabla$}

As befits a new method, elastography is being used in new applications which as yet lack sufficient strength of evidence to justify their inclusion in these Recommendations, though their exclusion should not be taken as implying that they may not prove to be of clinical value once more experience is gained. The topics below are an incomplete list of those that are of clinical interest but whose clinical value is still to be confirmed. 
Elastography of superficial lymph nodes, for example in the neck or inguinal regions, is a promising application, where an increase in stiffness would be expected in malignancy but might also occur in inflamed nodes $[177,178]$.

Intraoperative elastography has been applied to the brain to guide the surgeon to stiffer regions that represent tumours and improve the precision of their resection [179, 180].

Elastography of the uterine cervix to assess the softening that precedes normal dilatation before delivery is potentially important. Premature delivery is a major cause of fetal death, which could be reduced if a simple and reliable means of identifying premature softening could be developed [181].

Testicular tumours are harder than the surrounding gland on palpation and this might be a useful application of elastography to aid the distinction between the commoner malignancies and the rarer less invasive tumours such as Leydig cell tumours, which can be managed with tissue-sparing surgery [182].

Anal incontinence, most commonly an obstetrical injury, leads to scarring which is stiffer than the normal sphincter muscles; a preliminary report focusses on the presurgical findings, with promising results [128] whereas postoperative evaluation was disappointing [183]. Elastography has been used in rectal and anal carcinomas where it improves the discrimination between adenoma and cancer [129] and the differentiation of T2 and T3 stages of rectal cancer. Although this improved differentiation has so far not been evaluated, it seems convincing because inflammatory changes appear softer than the usually harder tumours.

Perineal ultrasound is an effective method for imaging perianal inflammatory lesions (e.g. in Crohn's disease) but is too rarely used. Generally speaking, acute inflammatory lesions are softer and chronic lesions harder in comparison to the surrounding tissue [184].

Arterial and plaque stiffness has been studied in preliminary investigations $[135,185,186]$ and might form a clinically useful way to assess vulnerable plaque.

Promising results have been reported on the clinical use of SE for tendon disease such as for common extensor origin tendons in order to depict tendon and fascia involvement in lateral epicondylitis [187], for plantar fascia where stiffness changes with age and disease [188] and for trigger finger, where there is increased stiffness of the flexor tendon which decreases after steroid injections [189]. Preliminary studies also show the potential use of strain elastography in localising myofascial trigger points to inject with botulin toxin [190] and for diagnosing and monitoring of inflammatory myopathies by showing changes in muscle stiffness in correlation with elevated serum markers [173]. Preliminary data are available on stiffness measurements and shear wave velocities of normal muscle and tendon using shear wave techniques [175, 191].

Other applications will no doubt emerge as more experience is gathered.

\section{Illustrations}

$\nabla$

Illustrations of most applications of USE described in the present article can be found at the webpage http://www.efsumb-atlas. org/elastography/.

\section{Abbreviations}

$\nabla$

$2 \mathrm{D}$ two-dimensions

$3 \mathrm{D}$ three-dimensions

ARFI acoustic radiation force impulse

AUROC area under the receiver operator characteristic curve

BI-RADS breast imaging reporting and data system

BMI body mass index

CrI credible interval

CEUS contrast enhanced ultrasound

EUS endoscopic ultrasound

GI gastro-intestinal

HCC hepatocellular carcinoma

ICC intraclass correlation coefficient*

IQR inter quartile range

$\mathrm{kPa} \quad$ kiloPascal

LS liver stiffness

NAFLD non-alcoholic fatty liver disease

NASH non-alcoholic steato-hepatitis

NPV negative predictive value

PPV positive predictive value

pSWE point shear wave elastography

ROC receiver operator characteristic

ROI region of interest

SE strain elastography

SNR signal-to-noise ratio

SRI strain rate imaging

SWE shear wave elastography

US ultrasound

USE ultrasound elastography

\section{Affiliations}

1 Div. of Radiology, Imperial and Kings Colleges, London, UK

2 Div. Internal Medicine, University of Bologna, Bologna Italy

3 The Joint Department of Physics, Division of Radiotherapy and Imaging, Institute of Cancer Research and Royal Marsden Hospital, NHS Foundation Trust, London, United Kingdom

4 Department of Internal Medicine I, Endocrinology and Diabetology, GoetheUniversity, Frankfurt, Germany

5 Adult Radiology, Paris Descartes University \& Necker University Hospital, France, Institut Langevin - Ondes et Images ESPCI Paris Tech, CNRS UMR 7587 INSERM U 979

6 National Centre for Ultrasound in Gastroenterology, Department of Medicine, Haukeland University Hospital, Bergen, Norway and Department of Clinical Medicine, University of Bergen, Norway

7 Department of Radiology, Innsbruck Medical University, Austria

8 Department of Gastroenterology and Hepatology, University of Medicine and Pharmacy "Victor Babeş" Timişoara, Romania

9 Div. of Radiology, University of Pavia, Policlinico San Matteo, Italy

10 Department of Radiological Sciences, Oncology and Pathology, Policlinico Umberto I, Univ. Sapienza, Rome, Italy

11 Department of Radiology, GB Rossi University Hospital, University of Verona, Italy

12 Div. of Radiology, University Hospital Heraklion, Crete, Greece

13 Ecole Supérieure de Physique et de Chimie de la Ville de Paris, France

14 Department of Internal Medicine I, Gastroenterology and Hepatology, Goethe-University, Frankfurt, Germany

15 National Centre for Ultrasound in Gastroenterology, Department of Medicine, Haukeland University Hospital, Bergen, Norway
* ICC definitions according to the correlation coefficients: Kappa $0-0.2$ indicate slight agreement; $0.21-0.4$, fair agreement; $0.41-0.6$, moderate agreement; $0.61-0.8$, substantial agreement; and $0.81-0.99$ almost perfect agreement [192]. 
${ }^{16}$ Div. Gastroenterology, Department of Internal Medicine, Krankenhaus Märkisch Oderland, Strausberg, Germany

17 Department of Obstetrics and Gynecology, Breast unit, University Greifswald, Germany

18 Department of Gastroenterology, Research Center of Gastroenterology and Hepatology, University of Medicine and Pharmacy, Craiova, Romania

19 Unit of Breast Imaging and Interventions, University Hospital SchleswigHolsten Campus Kiel, Germany

20 Div. Gastroenterology \& Oncology, Caritas Krankenhaus, Bad Mergentheim, Germany

\section{Acknowledgements}

The authors acknowledge the contribution of Prof.F. Frauscher, Austria, who gave advice for the section on the Prostate.

The unrestricted financial support provided by the following companies (listed in alphabetical order) to support the preparation of this document is gratefully acknowledged:

BK Medical, Echosens, Esaote, GE Healthcare, Hitachi Aloka, Philips, Siemens, SuperSonic Imagine and Toshiba.

Since USE technology is evolving rapidly, more detailed descriptions of the techniques related to individual equipment, beyond the general principles described in the Part 1 of the present document [1], will soon be added. Therefore, EFSUMB considered it more appropriate to invite interested readers to access this information directly from the supporting manufacturers' websites, which can be reached through the links in the EFSUMB web portal, under the term "Appendix" in the Guidelines section of the website (http://www.efsumb.org/guidelines/elasto-manufacturers-links.pdf).

\section{References}

1 Bamber J, Cosgrove D, Dietrich CF et al. EFSUMB Guidelines and Recommendations on the Clinical Use of Ultrasound Elastography. Part 1: Basic Principles and Technology. Ultraschall in Med 2013; 34: 169184

2 Claudon M, Dietrich CF, Choi BI et al. Guidelines and good clinical practice recommendations for contrast enhanced ultrasound (CEUS) in the liver-update 2012: a WFUMB-EFSUMB initiative in cooperation with representatives of AFSUMB, AIUM, ASUM, FLAUS and ICUS. Ultraschall in Med 2013; 34: 11-29

3 Castera L, Foucher J, Bernard PH et al. Pitfalls of liver stiffness measurement: a 5-year prospective study of 13,369 examinations. Hepatology 2010; 51: $828-835$

4 Gebo KA, Herlong HF, Torbenson MS et al. Role of liver biopsy in management of chronic hepatitis C: a systematic review. Hepatology 2002; 36: S161- 172

5 Seeff $L B$, Everson GT, Morgan TR et al. Complication rate of percutaneous liver biopsies among persons with advanced chronic liver disease in the HALT-C trial. Clin Gastroenterol Hepatol 2010; 8: 877-883

6 Stotland BR, Lichtenstein GR. Liver biopsy complications and routine ultrasound. Am J Gastroenterol 1996; 91: 1295-1296

7 Regev A, Berho M, Jeffers LJ et al. Sampling error and intraobserver variation in liver biopsy in patients with chronic HCV infection. Am J Gastroenterol 2002; 97: 2614-2618

8 Goertz RS, Egger C, Neurath MF et al. Impact of Food Intake, Ultrasound Transducer, Breathing Maneuvers and Body Position on Acoustic Radiation Force Impulse (ARFI) Elastometry of the Liver. Ultraschall in Med 2012; 33: 380-385

9 Millonig G, Friedrich S, Adolf $S$ et al. Liver stiffness is directly influenced by central venous pressure. J Hepatol 2010; 52: 206-210

10 Sagir A, Erhardt A, Schmitt M et al. Transient elastography is unreliable for detection of cirrhosis in patients with acute liver damage. Hepatology 2008; 47: $592-595$

11 Mederacke I, Wursthorn K, Kirschner J et al. Food intake increases liver stiffness in patients with chronic or resolved hepatitis $C$ virus infection. Liver Int 2009; 29: 1500-1506
12 Millonig G, Reimann FM, Friedrich S et al. Extrahepatic cholestasis increases liver stiffness (FibroScan) irrespective of fibrosis. Hepatology 2008; 48: $1718-1723$

13 Reiberger T, Ferlitsch A, Payer BA et al. Non-selective beta-blockers improve the correlation of liver stiffness and portal pressure in advanced cirrhosis. J Gastroenterol 2011; 47: 561-568

14 Karlas T, Pfrepper C, Wiegand J et al. Acoustic radiation force impulse imaging (ARFI) for non-invasive detection of liver fibrosis: examination standards and evaluation of interlobe differences in healthy subjects and chronic liver disease. Scand J Gastroenterol 2011; 46: 1458 1467

15 Piscaglia F, Salvatore V, Di Donato $R$ et al. Accuracy of VirtualTouch Acoustic Radiation Force Impulse (ARFI) imaging for the diagnosis of cirrhosis during liver ultrasonography. Ultraschall in Med 2011; 32: $167-175$

16 D'Onofrio M, Gallotti A, Mucelli RP. Tissue quantification with acoustic radiation force impulse imaging: Measurement repeatability and normal values in the healthy liver. Am J Roentgenol Am J Roentgenol 2010; 195: $132-136$

17 Talwalkar JA, Kurtz DM, Schoenleber SJ et al. Ultrasound-based transient elastography for the detection of hepatic fibrosis: systematic review and meta-analysis. Clin Gastroenterol Hepatol 2007; 5: $1214-$ 1220

18 Friedrich-Rust M, Ong MF, Martens S et al. Performance of transient elastography for the staging of liver fibrosis: a meta-analysis. Gastroenterology 2008; 134: 960-974

19 Tsochatzis EA, Gurusamy KS, Ntaoula S et al. Elastography for the diagnosis of severity of fibrosis in chronic liver disease: a meta-analysis of diagnostic accuracy. J Hepatol 2007; 54: 650-659

20 EASL. EASL Clinical Practice Guidelines: Management of hepatitis C virus infection. J Hepatology 2011; 55: 245 - 264

21 Chan HL, Wong GL, Choi PC et al. Alanine aminotransferase-based algorithms of liver stiffness measurement by transient elastography (Fibroscan) for liver fibrosis in chronic hepatitis B. J Viral Hepat 2009; 16: 36 44

22 Chon YE, Choi EH, Song KJ et al. Performance of transient elastography for the staging of liver fibrosis in patients with chronic hepatitis B: a meta-analysis. PLoS One 2012; 7: e44930

23 Wong VW, Vergniol J, Wong GL et al. Diagnosis of fibrosis and cirrhosis using liver stiffness measurement in nonalcoholic fatty liver disease. Hepatology 2010; 51: 454-462

24 de Ledinghen $V$, Wong $V W$, Vergniol J et al. Diagnosis of liver fibrosis and cirrhosis using liver stiffness measurement: comparison between $M$ and XL probe of FibroScan(R). J Hepatol 2012; 56: 833-839

25 Friedrich-Rust M, Hadji-Hosseini H, Kriener S et al. Transient elastography with a new probe for obese patients for non-invasive staging of non-alcoholic steatohepatitis. Eur Radiol 2010; 20: 2390 - 2396

26 Myers RP, Pomier-Layrargues G, Kirsch R et al. Feasibility and diagnostic performance of the FibroScan XL probe for liver stiffness measurement in overweight and obese patients. Hepatology 2012; 55: 199-208

27 de Ledinghen $V$, Vergniol J, Foucher $J$ et al. Feasibility of liver transient elastography with FibroScan using a new probe for obese patients. Liver Int 2010; 30: $1043-1048$

28 Adebajo CO, Talwalkar JA, Poterucha JJ et al. Ultrasound-based transient elastography for the detection of hepatic fibrosis in patients with recurrent hepatitis $C$ virus after liver transplantation: a systematic review and meta-analysis. Liver Transpl 2012; 18: 323-331

29 Vizzutti F, Arena $U$, Romanelli $R G$ et al. Liver stiffness measurement predicts severe portal hypertension in patients with HCV-related cirrhosis. Hepatology 2007; 45: 1290-1297

30 Bureau C, Metivier S, Peron JM et al. Transient elastography accurately predicts presence of significant portal hypertension in patients with chronic liver disease. Aliment Pharmacol Ther 2008; 27: 1261 -1268

31 Castera L, Le Bail B, Roudot-Thoraval F et al. Early detection in routine clinical practice of cirrhosis and oesophageal varices in chronic hepatitis C: comparison of transient elastography (FibroScan) with standard laboratory tests and non-invasive scores. J Hepatol 2009; 50: 59-68

32 Sporea I, Ratiu I, Sirli R et al. Value of transient elastography for the prediction of variceal bleeding. World J Gastroenterol 2011; 17: 2206 2210

33 Pritchett S, Cardenas A, Manning $D$ et al. The optimal cut-off for predicting large oesophageal varices using transient elastography is disease specific. J Viral Hepat 2011; 18: e75-80

34 Colecchia A, Montrone L, Scaioli E et al. Measurement of Spleen Stiffness to Evaluate Portal Hypertension and the Presence of Esophageal Vari- 
ces in Patients With HCV-Related Cirrhosis. Gastroenterology 2012; 143: $646-654$

35 Berzigotti A, Piscaglia F. Ultrasound in portal hypertension-part 1. Ultraschall in Med 2011; 32: 548 - 568

36 Vergniol J, Foucher J, Terrebonne E et al. Noninvasive tests for fibrosis and liver stiffness predict 5-year outcomes of patients with chronic hepatitis C. Gastroenterology 2011; 140: 1970-1979

37 Masuzaki R, Tateishi $R$, Yoshida $H$ et al. Prospective risk assessment for hepatocellular carcinoma development in patients with chronic hepatitis C by transient elastography. Hepatology 2009; 49: 1954-1961

38 Jung KS, Kim SU, Ahn SH et al. Risk assessment of hepatitis B virus-related hepatocellular carcinoma development using liver stiffness measurement (FibroScan). Hepatology 2011; 53: 885-894

39 Roulot D, Costes JL, Buyck JF et al. Transient elastography as a screening tool for liver fibrosis and cirrhosis in a community-based population aged over 45 years. Gut 2011; 60: $977-984$

40 Fraquelli M, Rigamonti C, Casazza $G$ et al. Reproducibility of transient elastography in the evaluation of liver fibrosis in patients with chronic liver disease. Gut 2007; 56: 968 -973

41 Bonino $F$, Arena $U$, Brunetto $M R$ et al. Liver stiffness, a non-invasive marker of liver disease: a core study group report. Antivir Ther 2010; 15: $69-78$

42 Friedrich-Rust $M$, Wunder K, Kriener S et al. Liver fibrosis in viral hepatitis: noninvasive assessment with acoustic radiation force impulse imaging versus transient elastography. Radiology 2009; 252: 595 - 604

43 Sporea I, Sirli R, Bota S et al. Is ARFI elastography reliable for predicting fibrosis severity in chronic HCV hepatitis? World J Radiol 2011; 3: $188-193$

44 Sporea I, Bota S, Peck-Radosavljevic $M$ et al. Acoustic Radiation Force Impulse Elastography for fibrosis evaluation in patients with chronic hepatitis C: An international multicenter study. Eur J Radiol 2012; 81: $4112-4118$

45 Rizzo L, Calvaruso V, Cacopardo B et al. Comparison of transient elastography and acoustic radiation force impulse for non-invasive staging of liver fibrosis in patients with chronic hepatitis C. Am J Gastroenterol 2011; 106: $2112-2120$

46 Sporea I, Bota S, Sirli $R$ et al. The value of ARFI elastography for fibrosis evaluation in patients with chronic hepatitis $C$ in comparison with liver biopsy - an international multicenter study. In, The International Liver Congress. Barcelona, Spani J Hepatol 2012: S420-S421

47 Yoneda M, Suzuki K, Kato S et al. Nonalcoholic fatty liver disease: USbased acoustic radiation force impulse elastography. Radiology 2010; 256: $640-647$

48 Friedrich-Rust $M$, Romen $D$, Vermehren J et al. Acoustic radiation force impulse-imaging and transient elastography for non-invasive assessment of liver fibrosis and steatosis in NAFLD. Eur J Radiol 2012; 81: e325-331

49 Crespo G, Fernandez-Varo G, Marino Z et al. ARFI, FibroScan(R), ELF, and their combinations in the assessment of liver fibrosis: A prospective study. J Hepatol 2012; 57: $281-287$

50 Friedrich-Rust M, NierhoffJ, Lupsor M et al. Performance of Acoustic Radiation Force Impulse imaging for the staging of liver fibrosis: a pooled meta-analysis. J Viral Hepat 2012; 19: e212-219

51 Toshima T, Shirabe K, Takeishi $K$ et al. New method for assessing liver fibrosis based on acoustic radiation force impulse: a special reference to the difference between right and left liver. J Gastroenterol 2011; 46: $705-711$

52 Bavu E, Gennisson JL, Couade $M$ et al. Noninvasive in vivo liver fibrosis evaluation using supersonic shear imaging: a clinical study on 113 hepatitis C virus patients. Ultrasound Med Biol 2011; 37: 1361 - 1373

53 Ferraioli G, Tinelli C, Dal BelloB et al. Accuracy of real-time shear wave elastography for assessing liver fibrosis in chronic hepatitis C: A pilot study. Hepatology 2012; 56: 2125-2133

54 Ferraioli G, Tinelli C, Zicchetti M et al. Reproducibility of real-time shear wave elastography in the evaluation of liver elasticity. Eur J Radiol 2012; 81: $3102-3106$

55 Yoon KT, Lim SM, Park JY et al. Liver Stiffness Measurement Using Acoustic Radiation Force Impulse (ARFI) Elastography and Effect of Necroinflammation. Dig Dis Sci 2012; 57: 1682 - 1691

56 Bota S, Sporea I, Peck-Radosavljevic $M$ et al. The influence of aminotransferase levels on liver stiffness assessed by Acoustic Radiation Force Impulse Elastography: A retrospective multicentre study. Dig Liver Dis 2013; DOI: doi.org/10.1016/j.dld.2013.1002.1008
57 Bota S, Sporea I, Sirli R et al. Factors that influence the correlation of acoustic radiation force impulse (ARFI), elastography with liver fibrosis. Med Ultrason 2011; 13: 135 - 140

58 Friedrich-Rust M, Ong MF, Herrmann E et al. Real-time elastography for noninvasive assessment of liver fibrosis in chronic viral hepatitis. Am J Roentgenol Am J Roentgenol 2007; 188: 758 - 764

59 Tatsumi C, Kudo M, Ueshima K et al. Noninvasive evaluation of hepatic fibrosis using serum fibrotic markers, transient elastography (FibroScan) and real-time tissue elastography. Intervirology 2008; $51: 27$ 33

60 Fujimoto K, Kato M, Kudo $M$ et al. Novel image analysis method using ultrasound elastography for noninvasive evaluation of hepatic fibrosis in patients with chronic hepatitis C. Oncology 2013; 84: 3-12

61 Ying $L$, Lin X, Xie ZL et al. Clinical utility of acoustic radiation force impulse imaging for identification of malignant liver lesions: a meta-analysis. Eur Radiol 2012; 22: 2798-2805

$62 \mathrm{Yu} \mathrm{H}$, Wilson SR. Differentiation of benign from malignant liver masses with Acoustic Radiation Force Impulse technique. Ultrasound Q 2011; 27: $217-223$

63 Onur MR, Poyraz AK, Ucak EE et al. Semiquantitative strain elastography of liver masses. J Ultrasound Med 2012; 31: 1061 - 1067

64 Guibal A, Boularan C, Bruce M et al. Evaluation of shearwave elastography for the characterisation of focal liver lesions on ultrasound. Eur Radiol 2013; 23: 1138 - 1149

65 Itoh A, Ueno E, Tohno E et al. Breast disease: clinical application of US elastography for diagnosis. Radiology 2006; 239: 341 - 350

66 Hatzung G, Grunwald S, Zygmunt M et al. Sonoelastography in the diagnosis of malignant and benign breast lesions: initial clinical experiences. Ultraschall in Med 2010; 31: 596-603

67 Cho N, Jang M, Lyou CY et al. Distinguishing benign from malignant masses at breast US: combined US elastography and color doppler US-influence on radiologist accuracy. Radiology 2012; 262: 80 - 90

68 Wojcinski S, Farrokh A, Weber S et al. Multicenter study of ultrasound real-time tissue elastography in 779 cases for the assessment of breast lesions: improved diagnostic performance by combining the BI-RADS (R)-US classification system with sonoelastography. Ultraschall in Med 2010; 31: 484-491

69 Zhi H, Xiao XY, Ou B et al. Could ultrasonic elastography help the diagnosis of small $(</=2 \mathrm{~cm})$ breast cancer with the usage of sonographic BI-RADS classification? Eur J Radiol 2012; 81: 3216 - 3221

70 Schaefer FK, Heer I, Schaefer PJ et al. Breast ultrasound elastography-results of 193 breast lesions in a prospective study with histopathologic correlation. Eur J Radiol 2011; 77: 450-456

71 Fischer T, Peisker U, Fiedor $S$ et al. Significant differentiation of focal breast lesions: raw data-based calculation of strain ratio. Ultraschall in Med 2012; 33: $372-379$

72 Hall FM. Sonography of the breast: controversies and opinions. Am J Roentgenol 1997; 169: 1635-1636

73 Isermann $R$, Grunwald S, Hatzung $G$ et al. Breast lesion sizing by Bmode imaging and sonoelastography in comparison to histopathological sizing-a prospective study. Ultraschall in Med 2011; 32: S21 - 26

74 Barr RG, Destounis S, Lackey LB et al. Evaluation of breast lesions using sonographic elasticity imaging: a multicenter trial. J Ultrasound Med 2012; $31: 281-287$

75 Gong X, Xu Q Xu Z et al. Real-time elastography for the differentiation of benign and malignant breast lesions: a meta-analysis. Breast Cancer Res Treat 2011; 130: $11-18$

76 Sadigh G, Carlos RC, Neal CH et al. Accuracy of quantitative ultrasound elastography for differentiation of malignant and benign breast abnormalities: a meta-analysis. Breast Cancer Res Treat 2012; 134: 923-931

77 Booi RC, Carson PL, O'Donnell M et al. Characterization of cysts using differential correlation coefficient values from two dimensional breast elastography: preliminary study. Ultrasound Med Biol 2008; 34: 12 -21

78 Cho N, Moon WK, Chang JM et al. Aliasing artifact depicted on ultrasound (US)-elastography for breast cystic lesions mimicking solid masses. Acta Radiol 2011; 52: 3-7

79 Barr RG, Lackey AE. The utility of the "bull's-eye" artifact on breast elasticity imaging in reducing breast lesion biopsy rate. Ultrasound Q 2011; 27: 151 - 155

80 Barr RG. Shear wave imaging of the breast: still on the learning curve. J Ultrasound Med 2012; 31: 347-350

81 Athanasiou A, Tardivon A, Tanter $M$ et al. Breast lesions: quantitative elastography with supersonic shear imaging - preliminary results. Radiology 2010; 256: 297-303 
82 Evans A, Whelehan P, Thomson K et al. Quantitative shear wave ultrasound elastography: initial experience in solid breast masses. Breast Cancer Res 2010; 12: R104

83 Berg WA, Cosgrove DO, Dore CJ et al. Shear-wave elastography improves the specificity of breast US: the BE1 multinational study of 939 masses. Radiology 2012; 262: 435 - 449

84 Cosgrove DO, Berg WA, Dore CJ et al. Shear wave elastography for breast masses is highly reproducible. Eur Radiol 2011; 22: $1023-1032$

85 Schaefer FKW, Berg W, Cosgrove D et al. ShearWave ${ }^{\mathrm{TM}}$ Elastography worldwide breast trial model: Can additional SWE-features support downgrading BIRADS 3 to BI-RADS 2'? Abstract European Congress of Radiology 2012: p216

86 Tozaki M, Isobe S, Sakamoto M. Combination of elastography and tissue quantification using the acoustic radiation force impulse (ARFI) technology for differential diagnosis of breast masses. Jpn J Radiol 2012; 30: $659-670$

87 Chang JM, Moon WK, Cho N et al. Breast mass evaluation: factors influencing the quality of US elastography. Radiology 2011; 259: 59-64

88 Cespedes I, Ophir J, Ponnekanti H et al. Elastography: elasticity imaging using ultrasound with application to muscle and breast in vivo. Ultrason Imaging 1993; $15: 73-88$

89 Garra BS, Cespedes EI, Ophir J et al. Elastography of breast lesions: initial clinical results. Radiology 1997; 202: 79-86

90 Krouskop TA, Wheeler TM, Kallel F et al. Elastic moduli of breast and prostate tissues under compression. Ultrason Imaging 1998; 20: $260-274$

91 Samani A, Zubovits J, Plewes D. Elastic moduli of normal and pathological human breast tissues: an inversion-technique-based investigation of 169 samples. Phys Med Biol 2007; 52: 1565 - 1576

92 Reiners $C$, Wegscheider K, Schicha H et al. Prevalence of thyroid disorders in the working population of Germany: ultrasonography screening in 96,278 unselected employees. Thyroid 2004; 14: 926-932

93 Gharib H, Papini E, Paschke R et al. American Association of Clinical Endocrinologists, Associazione Medici Endocrinologi, and European Thyroid Association medical guidelines for clinical practice for the diagnosis and management of thyroid nodules: executive summary of recommendations. J Endocrinol Invest 2010; 33: 51 - 56

94 Gharib H, Papini E, Paschke R et al. American Association of Clinical Endocrinologists, Associazione Medici Endocrinologi, and EuropeanThyroid Association Medical Guidelines for Clinical Practice for the Diagnosis and Management of Thyroid Nodules. Endocr Pract 2010; 16: 1 -43

95 Asteria C, Giovanardi A, Pizzocaro A et al. US-elastography in the differential diagnosis of benign and malignant thyroid nodules. Thyroid 2008; $18: 523-531$

96 Vorlander C, Wolff J, Saalabian S et al. Real-time ultrasound elastography-a noninvasive diagnostic procedure for evaluating dominant thyroid nodules. Langenbecks Arch Surg 2010; 395: 865 - 871

97 Bojunga J, Herrmann E, Meyer $G$ et al. Real-time elastography for the differentiation of benign and malignant thyroid nodules: a meta-analysis. Thyroid 2010; 20: 1145 - 1150

98 Moon HJ, Kim EK, Yoon JH et al. Clinical implication of elastography as a prognostic factor of papillary thyroid microcarcinoma. Ann Surg Oncol 2012; 19: $2279-2287$

99 Cantisani V, D'Andrea V, Biancari F et al. Prospective evaluation of multiparametric ultrasound and quantitative elastosonography in the differential diagnosis of benign and malignant thyroid nodules: Preliminary Experience. Eur J Radiol 2012; 81: 2678 - 2683

100 Ning CP, Jiang SQ Zhang T et al. The value of strain ratio in differential diagnosis of thyroid solid nodules. Eur J Radiol 2012; 81: 286-291

101 Wang Y, Dan HJ, Dan HY et al. Differential diagnosis of small single solid thyroid nodules using real-time ultrasound elastography. J Int Med Res 2010; 38: 466-472

102 Lippolis PV, Tognini S, Materazzi G et al. Is elastography actually useful in the presurgical selection of thyroid nodules with indeterminate cytology? J Clin Endocrinol Metab 2011; 96: E1826-1830

103 Cantisani V, Ulisse S, Guaitoli E et al. Q-elastography in the presurgical diagnosis of thyroid nodules with indeterminate cytology. PLoS One 2012; 7: e50725

104 Sebag F, Vaillant-Lombard J, Berner C et al. Shear wave elastography: a new ultrasound imaging mode for the differential diagnosis of benign and malignant thyroid nodules. J Clin Endocrinol Metab 2010; 95: $5281-5288$

105 Bhatia KS, Tong CS, Cho CC et al. Shear wave elastography of thyroid nodules in routine clinical practice: preliminary observations and utility for detecting malignancy. Eur Radiol 2012; 22 (11): 2397 2406

106 Veyrieres JB, Albarel F, Lombard JV et al. A threshold value in Shear Wave elastography to rule out malignant thyroid nodules: a reality? Eur J Radiol 2012; 81: 3965 - 3972

107 Bojunga J, Dauth N, Berner C et al. Acoustic radiation force impulse imaging for differentiation of thyroid nodules. PLoS One 2012; 7 : e42735

108 Friedrich-Rust M, Romenski O, Meyer G et al. Acoustic Radiation Force Impulse-Imaging for the evaluation of the thyroid gland: a limited patient feasibility study. Ultrasonics 2012; 52: 69-74

109 Hong Y, Liu X, Li Z et al. Real-time ultrasound elastography in the differential diagnosis of benign and malignant thyroid nodules. J Ultrasound Med 2009; 28: 861 - 867

110 Rago T, Santini F, Scutari M et al. Elastography: new developments in ultrasound for predicting malignancy in thyroid nodules. J Clin Endocrinol Metab 2007; 92: 2917-2922

$111 \mathrm{Kim} J \mathrm{~K}$, Baek JH, Lee JH et al. Ultrasound elastography for thyroid nodules: a reliable study? Ultrasound Med Biol 2012; 38: 1508-1513

112 Nylund $\mathrm{K}$, Hausken T, Gilja $\mathrm{OH}$. Ultrasound and inflammatory bowel disease. Ultrasound Q 2010; 26: 3-15

113 Gilja $\mathrm{OH}$, Heimdal A, Hausken $\mathrm{T}$ et al. Strain during gastric contractions can be measured using Doppler ultrasonography. Ultrasound Med Biol 2002; 28: 1457 - 1465

114 Stidham RW, Xu J, Johnson LA et al. Ultrasound elasticity imaging for detecting intestinal fibrosis and inflammation in rats and humans with Crohn's disease. Gastroenterology 2011; 141: 819-826 e811

115 Rustemovic N, Cukovic-Cavka S, Brinar M et al. A pilot study of transrectal endoscopic ultrasound elastography in inflammatory bowel disease. BMC Gastroenterol 2011; 11: 113

116 Ishikawa $D$, Ando $T$, Watanabe 0 et al. Images of colonic real-time tissue sonoelastography correlate with those of colonoscopy and may predict response to therapy in patients with ulcerative colitis. BMC Gastroenterol 2011; 11: 29

117 Gilja $\mathrm{OH}$. Ultrasound of the stomach-the EUROSON lecture 2006. Ultraschall in Med 2007; 28: 32 - 39

118 Ahmed AB, Matre K, Hausken T et al. Rome III subgroups of functional dyspepsia exhibit different characteristics of antral contractions measured by strain rate imaging - a pilot study. Ultraschall in Med 2012; 33: E233-240

119 Heimdal A. Strain Rate Imaging- Anew tool for studying the GI tract. In: Odegaard S, Gilja OH, Gregersen H editors. Basic and new aspects of gastrointestinal ultrasonography Singapore: World Scientific; 2005: $243-263$

120 Matre $K$, Ahmed $A B$, Gregersen $H$ et al. In vitro evaluation of ultrasound Doppler strain rate imaging: modification for measurement in a slowly moving tissue phantom. Ultrasound Med Biol 2003; 29: $1725-1734$

121 Ahmed $A B$, Gilja $\mathrm{OH}$, Gregersen $\mathrm{H}$ et al. In vitro strain measurement in the porcine antrum using ultrasound doppler strain rate imaging. Ultrasound Med Biol 2006; 32: $513-522$

122 Ahmed $A B$, Gilja $\mathrm{OH}$, Hausken $\mathrm{T}$ et al. Strain measurement during antral contractions by ultrasound strain rate imaging: influence of erythromycin. Neurogastroenterol Motil 2009; 21: 170-179

123 Hirche TO, Ignee A, Barreiros AP et al. Indications and limitations of endoscopic ultrasound elastography for evaluation of focal pancreatic lesions. Endoscopy 2008; 40: $910-917$

124 Giovannini $M$, Botelberge T, Bories $E$ et al. Endoscopic ultrasound elastography for evaluation of lymph nodes and pancreatic masses: a multicenter study. World J Gastroenterol 2009; 15: 1587-1593

125 Săftoiu A, Vilmann P, Gorunescu F et al. Efficacy of an artificial neural network-based approach to endoscopic ultrasound elastography in diagnosis of focal pancreatic masses. Clin Gastroenterol Hepatol 2012; 10: $84-90$

126 Janssen J, Schlorer E, Greiner L. EUS elastography of the pancreas: feasibility and pattern description of the normal pancreas, chronic pancreatitis, and focal pancreatic lesions. Gastrointest Endosc 2007; 65: $971-978$

127 Larsen MH, Fristrup C, Hansen TP et al. Endoscopic ultrasound, endoscopic sonoelastography, and strain ratio evaluation of lymph nodes with histology as gold standard. Endoscopy 2012; 44: 759-766

128 Allgayer H, Ignee A, Dietrich CF. Endosonographic elastography of the anal sphincter in patients with fecal incontinence. Scand J Gastroenterol 2010; 45: 30 - 38 
129 Waage JE, Havre RF, Odegaard $S$ et al. Endorectal elastography in the evaluation of rectal tumours. Colorectal Dis 2011; 13: 1130-1137

130 Paterson S, Duthie F, Stanley AJ. Endoscopic ultrasound-guided elastography in the nodal staging of oesophageal cancer. World J Gastroenterol 2012; 18: 889-895

131 Fusaroli P, Saftoiu A, Mancino MG et al. Techniques of image enhancement in EUS (with videos). Gastrointest Endosc 2011; 74: 645-655

132 Săftoiu A, Vilmann $P$, Hassan $H$ et al. Analysis of endoscopic ultrasound elastography used for characterisation and differentiation of benign and malignant lymph nodes. Ultraschall in Med 2006; 27: $535-542$

133 Săftoiu A, Vilmann P, Gorunescu F et al. Neural network analysis of dynamic sequences of EUS elastography used for the differential diagnosis of chronic pancreatitis and pancreatic cancer. Gastrointest Endosc 2008; 68: 1086-1094

134 Săftoiu A, Vilmann P, Gorunescu F et al. Accuracy of endoscopic ultrasound elastography used for differential diagnosis of focal pancreatic masses: a multicenter study. Endoscopy 2011; 43: 596-603

135 Larsen $M H$, Fristrup CW, Mortensen MB. Intra- and interobserver agreement of endoscopic sonoelastography in the evaluation of lymph nodes. Ultraschall in Med 2011; 32: E45-50

136 Dietrich C. Echtzeit-Gewebeelastografie. Anwendungsmöglichkeiten nicht nur im Gastrointestinaltrakt. Endoskopie Heute 2010; 23: $177-212$

137 Dietrich CF, Hirche TO, Ott M et al. Real-time tissue elastography in the diagnosis of autoimmune pancreatitis. Endoscopy 2009; 41: 718 - 720

138 Iglesias-Garcia J, Larino-Noia J, Abdulkader I et al. Quantitative endoscopic ultrasound elastography: an accurate method for the differentiation of solid pancreatic masses. Gastroenterology 2010; 139: $1172-1180$

139 Itokawa $F$, Itoi $T$, Sofuni A et al. EUS elastography combined with the strain ratio of tissue elasticity for diagnosis of solid pancreatic masses. J Gastroenterol 2011; 46: 843-853

$140 \mathrm{Mei}$ M, Ni J, Liu $\mathrm{D}$ et al. EUS elastography for diagnosis of solid pancreatic masses: a meta-analysis. Gastrointest Endosc 2012; 77: 578 - 589

141 Pei Q Zou X, Zhang X et al. Diagnostic value of EUS elastography in differentiation of benign and malignant solid pancreatic masses: a meta-analysis. Pancreatology 2012; 12: 402-408

142 D'Onofrio M, Gallotti A, Salvia R et al. Acoustic radiation force impulse (ARFI) ultrasound imaging of pancreatic cystic lesions. Eur J Radiol 2011; 80: 241 - 244

143 Piscaglia F, Nolsoe C, Dietrich CF et al. The EFSUMB Guidelines and Recommendations on the Clinical Practice of Contrast Enhanced Ultrasound (CEUS): update 2011 on non-hepatic applications. Ultraschall in Med 2012; 33: 33-59

144 Jenssen C, Dietrich $C F$. Endoscopic ultrasound-guided fine-needle aspiration biopsy and trucut biopsy in gastroenterology - An overview. Best Pract Res Clin Gastroenterol 2009; 23: 743 - 759

145 Janssen J. [(E)US elastography: current status and perspectives]. Z Gastroenterol 2008; 46: $572-579$

146 Janssen J, Dietrich CF, Will U et al. Endosonographic elastography in the diagnosis of mediastinal lymph nodes. Endoscopy 2007; 39: $952-957$

$147 \mathrm{Xu}$ W, Shi J, Zeng X et al. EUS elastography for the differentiation of benign and malignant lymph nodes: a meta-analysis. Gastrointest Endosc 2011; 74: 1001-1009

148 Kelloff GJ, Choyke P, Coffey DS. Challenges in clinical prostate cancer: role of imaging. Am J Roentgenol Am J Roentgenol 2009; 192: $1455-1470$

149 Singh H, Canto EI, Shariat SF et al. Predictors of prostate cancer after initial negative systematic 12 core biopsy. J Urol 2004; 171: 1850 1854

150 Ashley RA, Inman BA, Routh JC et al. Reassessing the diagnostic yield of saturation biopsy of the prostate. Eur Urol 2008; 53: 976-981

151 Onur R, Littrup PJ, Pontes JE et al. Contemporary impact of transrectal ultrasound lesions for prostate cancer detection. J Urol 2004; 172 : $512-514$

152 Salomon G, Kollerman J, Thederan I et al. Evaluation of prostate cancer detection with ultrasound real-time elastography: a comparison with step section pathological analysis after radical prostatectomy. Eur Urol 2008; 54: 1354-1362

153 Pallwein L, Mitterberger M, Struve P et al. Real-time elastography for detecting prostate cancer: preliminary experience. BJU Int 2007; 100: $42-46$
154 Brock M, von Bodman C, Sommerer F et al. Comparison of real-time elastography with grey-scale ultrasonography for detection of organ-confined prostate cancer and extra capsular extension: a prospective analysis using whole mount sections after radical prostatectomy. BJU Int 2012; 108: E217-222

155 Brock M, von Bodman C, Palisaar RJ et al. The impact of real-time elastography guiding a systematic prostate biopsy to improve cancer detection rate: a prospective study of 353 patients. J Urol 2012; 187: $2039-2043$

156 Kapoor A, Mahajan G, Sidhu BS. Real-time elastography in the detection of prostate cancer in patients with raised PSA level. Ultrasound Med Biol 2011; 37: 1374-1381

157 Walz J, Marcy M, Pianna JT et al. Identification of the prostate cancer index lesion by real-time elastography: considerations for focal therapy of prostate cancer. World J Urol 2011; 29: 589-594

158 Aigner F, Pallwein L, Junker D et al. Value of real-time elastography targeted biopsy for prostate cancer detection in men with prostate specific antigen $1.25 \mathrm{ng} / \mathrm{ml}$ or greater and $4.00 \mathrm{ng} / \mathrm{ml}$ or less. J Urol 2010; 184: $913-917$

159 Aboumarzouk OM, Ogston S, Huang $Z$ et al. Diagnostic accuracy of transrectal elastosonography (TRES) imaging for the diagnosis of prostate cancer: a systematic review and meta-analysis. BJU Int 2012; 110: $1414-1423$

160 Kamoi K, Okihara K, Ochiai A et al. The utility of transrectal real-time elastography in the diagnosis of prostate cancer. Ultrasound Med Biol 2008; 34: $1025-1032$

161 Bercoff J, Tanter M, Fink M. Supersonic shear imaging: a new technique for soft tissue elasticity mapping. IEEE Trans Ultrason Ferroelectr Freq Control 2004; 51: 396 - 409

162 Correas JM, Khairoune A, Tissier AM et al. Trans-rectal quantitative shear wave elastography: application to prostate cancer. A feasibility study. Abstract, European Congress of Radiology, Vienna, 2012

163 Barr RG, Memo R, Schaub CR. Shear wave ultrasound elastography of the prostate: initial results. Ultrasound Q 2012; 28: 13-20

164 Levinson SF, Shinagawa M, Sato T. Sonoelastic determination of human skeletal muscle elasticity. J Biomech 1995; 28: 1145-1154

165 Drakonaki EE, Allen GM, Wilson DJ. Ultrasound elastography for musculoskeletal applications. Br J Radiol 2012; 85: 1435-1445

166 Pedersen $M$, Fredberg $U$, Langberg $H$. Sonoelastography as a Diagnostic Tool in the Assessment of Musculoskeletal Alterations: A Systematic Review. Ultraschall in Med 2012; 33: 441 - 446

167 Drakonaki EE, Allen GM, Wilson DJ. Real-time ultrasound elastography of the normal Achilles tendon: reproducibility and pattern description. Clin Radiol 2009; 64: 1196-1202

168 De Zordo T, Chhem R, Smekal $V$ et al. Real-time sonoelastography: findings in patients with symptomatic achilles tendons and comparison to healthy volunteers. Ultraschall in Med 2010; 31: 394- 400

169 De Zordo T, Fink C, Feuchtner GM et al. Real-time sonoelastography findings in healthy Achilles tendons. Am J Roentgenol Am J Roentgenol 2009; 193: W134-138

170 Tan S, Kudas S, Ozcan AS et al. Real-time sonoelastography of the Achilles tendon: pattern description in healthy subjects and patients with surgically repaired complete ruptures. Skeletal Radiol 2012; 41: $1067-1072$

171 Klauser AS, Faschingbauer R, Jaschke WR. Is sonoelastography of value in assessing tendons? Semin Musculoskelet Radiol 2010; 14: 323 - 333

172 Klauser AS, Myamoto H, Tamegger $M$ et al. Achilles tendon assessed with sonoelastography: histologic agreement. Radiology 2013; DOI: 10.1148/radiol.13121936

173 Botar-Jid C, Damian L, Dudea SM et al. The contribution of ultrasonography and sonoelastography in assessment of myositis. Med Ultrason 2010; 12 : $120-126$

174 Vasilescu D, Dudea S, Botar-Jid C et al. Sonoelastography contribution in cerebral palsy spasticity treatment assessment, preliminary report: a systematic review of the literature apropos of seven patients. Med Ultrason 2010; 12: 306-310

175 Kwon DR, Park GY, Lee SU et al. Spastic cerebral palsy in children: dynamic sonoelastographic findings of medial gastrocnemius. Radiology 2012; 263: 794-801

176 Park GY, Kwon DR. Sonoelastographic evaluation of medial gastrocnemius muscles intrinsic stiffness after rehabilitation therapy with botulinum toxin a injection in spastic cerebral palsy. Arch Phys Med Rehabil 2012; 93: 2085-2089 
177 Bhatia KS, Tong CS, Cho CC et al. Shear wave elastography of thyroid nodules in routine clinical practice: preliminary observations and utility for detecting malignancy. Eur Radiol 2012; 22: 2397-2406

178 Lyshchik A, Higashi T, Asato R et al. Cervical lymph node metastases: diagnosis at sonoelastography-initial experience. Radiology 2007; 243: $258-267$

179 Selbekk T, Bang J, Unsgaard G. Strain processing of intraoperative ultrasound images of brain tumours: initial results. Ultrasound Med Biol 2005; 31: 45-51

180 Chakraborty A, Bamber JC, Dorward NL. Preliminary investigation into the use of ultrasound elastography during brain tumour resection. Ultrasound 2012; 20: $33-40$

181 House M, Feltovich H, Hall TJ et al. Three-dimensional, extended fieldof-view ultrasound method for estimating large strain mechanical properties of the cervix during pregnancy. Ultrason Imaging 2012; 34: $1-14$

182 Kantarci F, Cebi OlgunD, Mihmanli I. Shear-wave elastography of segmental infarction of the testis. Korean J Radiol 2012; 13: 820-822

183 Allgayer H, Zipse S, Crispin A et al. Endorectal ultrasound and real-time elastography in patients with fecal incontinence following anorectal surgery: A prospective comparison evaluating short- and long-term outcomes in irradiated and non-irradiated patients. Z Gastroenterol 2012; 50: 1281 - 1286

184 Dietrich CF, Barreiros AP, Nuernberg D et al. [Perianal ultrasound]. Z Gastroenterol 2008; 46: 625-630
185 Maurice RL, Soulez G, Giroux MF et al. Noninvasive vascular elastography for carotid artery characterization on subjects without previous history of atherosclerosis. Med Phys 2008; 35: 3436-3443

186 Couade M, Pernot M, Prada C et al. Quantitative assessment of arterial wall biomechanical properties using shear wave imaging. Ultrasound Med Biol 2010; 36: 1662 - 1676

187 De Zordo T, Lill SR, Fink C et al. Real-time sonoelastography of lateral epicondylitis: comparison of findings between patients and healthy volunteers. Am J Roentgenol Am J Roentgenol 2009; 193: 180 - 185

$188 \mathrm{Wu} \mathrm{CH}$, Chang KV, Mio S et al. Sonoelastography of the plantar fascia. Radiology 2011; 259: 502 - 507

189 Miyamoto H, Miura T, Isayama $\mathrm{H}$ et al. Stiffness of the first annular pulley in normal and trigger fingers. J Hand Surg Am 2011; 36: 1486 - 1491

190 Sikdar S, Shah JP, Gebreab T et al. Novel applications of ultrasound technology to visualize and characterize myofascial trigger points and surrounding soft tissue. Arch Phys Med Rehabil 2009; 90: $1829-1838$

191 Arda K, Ciledag N, Aktas E et al. Quantitative assessment of normal soft-tissue elasticity using shear-wave ultrasound elastography. Am J Roentgenol Am J Roentgenol 2011; 197: 532-536

192 Landis JR, Koch GG. An application of hierarchical kappa-type statistics in the assessment of majority agreement among multiple observers. Biometrics 1977; 33: 363-374 